\title{
Label-Free Comparative Proteomics of Differentially Expressed Mycobacterium tuberculosis Protein in Rifampicin-Related Drug-Resistant Strains
}

\author{
Nadeem Ullah ${ }^{1,+}$, Ling Hao ${ }^{1,+}$, Jo-Lewis Banga Ndzouboukou ${ }^{1,+} \oplus$, Shiyun Chen ${ }^{2}$, Yaqi $\mathrm{Wu}^{1}{ }^{1}$, Longmeng $\mathrm{Li}^{1}$, \\ Eman Borham Mohamed ${ }^{1}$, Yangbo $\mathrm{Hu}^{2, *}$ and Xionglin Fan ${ }^{1, *} \mathbb{C}$
}

1 Department of Pathogen Biology, School of Basic Medicine, Tongji Medical College, Huazhong University of Science and Technology, Wuhan 430030, China; nadeemullah2016@hotmail.com (N.U.); d201781128@hust.edu.cn (L.H.); bangas19@yahoo.fr (J.-L.B.N.); yaqiwu@ustc.edu.cn (Y.W.); d201881254@hust.edu.cn (L.L.); emanborham831@gmail.com (E.B.M.)

2 CAS Key Laboratory of Special Pathogens and Biosafety, Institute of Virology, Chinese Academy of Sciences, Wuhan 430071, China; shiyunchen956@gmail.com

* Correspondence: xlfan@hust.edu.cn (X.F.); ybhu@wh.iov.cn (Y.H.)

+ These authors contributed equally to this paper.

check for updates

Citation: Ullah, N.; Hao, L.; Banga Ndzouboukou, J.-L.; Chen, S.; Wu, Y.; Li, L.; Borham Mohamed, E.; Hu, Y.; Fan, X. Label-Free Comparative Proteomics of Differentially Expressed Mycobacterium tuberculosis Protein in Rifampicin-Related Drug-Resistant Strains. Pathogens 2021, 10, 607. https://doi.org/ $10.3390 /$ pathogens 10050607

Academic Editor: Enrico Lavezzo

Received: 19 March 2021

Accepted: 10 May 2021

Published: 15 May 2021

Publisher's Note: MDPI stays neutral with regard to jurisdictional claims in published maps and institutional affiliations.

Copyright: (c) 2021 by the authors Licensee MDPI, Basel, Switzerland. This article is an open access article distributed under the terms and conditions of the Creative Commons Attribution (CC BY) license (https:// creativecommons.org/licenses/by/ $4.0 /)$.

\begin{abstract}
Rifampicin (RIF) is one of the most important first-line anti-tuberculosis (TB) drugs, and more than $90 \%$ of RIF-resistant (RR) Mycobacterium tuberculosis clinical isolates belong to multidrugresistant (MDR) and extensively drug-resistant (XDR) TB. In order to identify specific candidate target proteins as diagnostic markers or drug targets, differential protein expression between drugsensitive (DS) and drug-resistant (DR) strains remains to be investigated. In the present study, a label-free, quantitative proteomics technique was performed to compare the proteome of DS, RR, MDR, and XDR clinical strains. We found iniC, Rv2141c, folB, and Rv2561 were up-regulated in both RR and MDR strains, while fadE9, espB, espL, esxK, and Rv3175 were down-regulated in the three DR strains when compared to the DS strain. In addition, $1 p r F$, mce2R, mce2B, and Rv2627c were specifically expressed in the three DR strains, and 41 proteins were not detected in the DS strain. Functional category showed that these differentially expressed proteins were mainly involved in the cell wall and cell processes. When compared to the RR strain, Rv2272, smtB, lpqB, icd1, and folK were up-regulated, while esxK, PPE19, Rv1534, rpmI, ureA, tpx, mpt64, frr, Rv3678c, esxB, esxA, and espL were down-regulated in both MDR and XDR strains. Additionally, nrp, PPE3, mntH, Rv1188, Rv1473, nadB, PPE36, and sseA were specifically expressed in both MDR and XDR strains, whereas 292 proteins were not identified when compared to the RR strain. When compared between MDR and XDR strains, 52 proteins were up-regulated, while 45 proteins were down-regulated in the XDR strain. 316 proteins were especially expressed in the XDR strain, while 92 proteins were especially detected in the MDR strain. Protein interaction networks further revealed the mechanism of their involvement in virulence and drug resistance. Therefore, these differentially expressed proteins are of great significance for exploring effective control strategies of DR-TB.
\end{abstract}

Keywords: rifampicin; proteomics; label-free; Mycobacterium tuberculosis; drug resistance

\section{Introduction}

Tuberculosis (TB) remains one of the deadliest infectious diseases worldwide, resulting in 10 million new cases and 1.45 million deaths each year [1]. Currently available anti-TB drugs and vaccines have proved insufficient to contain this scourge. Moreover, the emergence and amplification of multidrug-resistant (MDR) and extensively drug-resistant (XDR) Mycobacterium tuberculosis strains have brought serious trouble to current TB prevention and treatment. Early diagnosis of drug-resistant TB (DR-TB) is conducive to timely adjustment of drug regimens for effective cure of TB, thus blocking the spread of DR-TB. 
Therefore, there is an urgent need to identify candidate targets that might be used for designing early, rapid, and sensitive DR-TB diagnostic and monitoring techniques [2].

Proteomic studies provide a novel implementable strategy to combat drug resistance and present a direct way to describe and identify novel target proteins involved in drug resistance directly or indirectly [3]. MDR-TB is TB-resistant to both rifampicin (RIF) and isoniazid (INH), the two vital drugs of the first-line anti-TB agents [4,5]. INH is critically significant after stimulation acts to prevent mycolic acid synthesis and mycobacterial cell wall formation [6]. RIF binds to $\beta$ subunit of DNA-dependent RNA polymerase and interferes with RNA transcription and elongation. The drug-resistance mechanism of various anti-TB drugs is mainly attributed to specific mutations in the target genes $[7,8]$. Some genes such as $r p o B$ and $r p o C$ are currently reported to be related to RIF resistance, while $k a t G, a h p C$, fabG1, kasA, ndh, and inhA are noted for INH resistance $[9,10]$. However, no genes have been found to cause cross-resistance between both RIF and INH. RIF-resistant (RR) strains have increased through their widespread use. Due to its similar resistance to other drugs, especially INH, the RR strain may be considered an alternative MDR-TB marker [11,12]. Currently, diagnostic methods used in hospitals are Drug Susceptibility Testing (DST), Gene Xpert MTB/RIF assay, and Hain test [13]. However, the problem with current diagnostic methods used in a hospital is the slow growth of M. tuberculosis, and underlying potential biological safety threats remain insufficient [14]. Xpert MTB/RIF only detects RIF resistance, unable to identify MDR-TB in its earliest form, such as INH monoresistance. In addition, it must regularly be used together with other tests, i.e., DST, to check and identify each $M$. tuberculosis isolate from the whole resistance phenotype [15,16]. In past decades, modern omics methods such as proteomics have had broad application prospects in finding new drug targets due to their complex bacteriological and biochemical characteristics. Proteomics approaches are progressively popular for addressing large-scale and small-scale hypotheses associated with microbial pathogens [2,17]. They constitute an efficient method for determining possible targets for drug development, biomarker discovery, identifying proteins, and drug resistance of pathogens [18].

Previous studies have shown that various chemical labelling techniques lead to limited complementary quantitative information among identified proteins [19]. The label-free quantification (LFQ) approach is mostly based on molecular biophysical properties without conjugated labels, which can avoid false positives and offer more reliable and repeatable test outcomes [20]. In order to sufficiently characterize biomarkers for various DR-TB severity conditions and screen distinct proteins in different stages of TB, the LFQ proteomics technique was used to compare the proteome of drug-sensitive (DS), RIF-resistant (RR), MDR, and XDR strains.

\section{Results}

\subsection{Up and Down-Regulated Proteins in the RR, MDR, and XDR vs. DS Strains}

A total of 2515 proteins were identified through a LFQ technique in DS, RR, MDR, and XDR strains. Heatmaps were generated to visualize the expressions and the clusters of the up-regulated or down-regulated proteins in the RR, MDR, XDR, and DS strains based on their $\log 2$ ratios of LFQ intensity $(p<0.05)$. When compared to the DS strain, 58 proteins were up-regulated, while 82 proteins were down-regulated in the RR strain (Figure 1A). Sixty one proteins were significantly increased, while 52 proteins were decreased in the MDR strain (Figure 1B). In addition, 56 proteins were found to be expressed at elevated levels, while 66 proteins showed lower expression in the XDR strain (Figure 1C). 
A

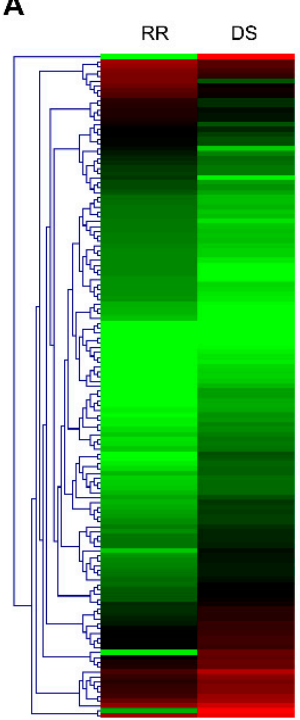

B

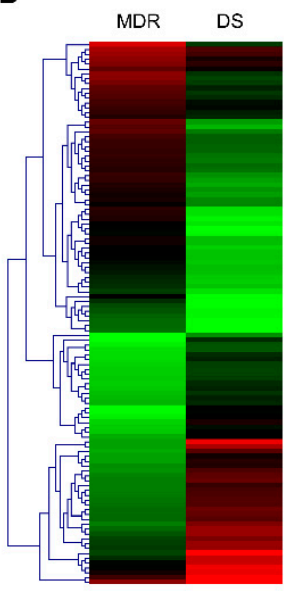

C

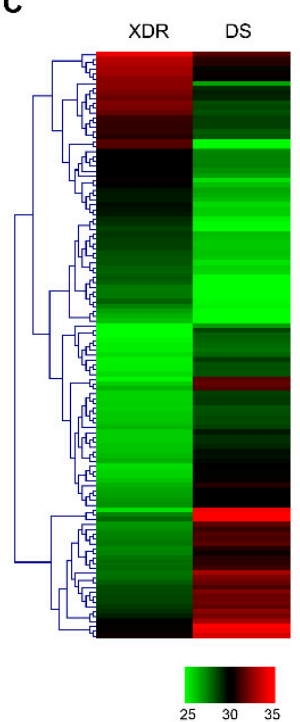

D

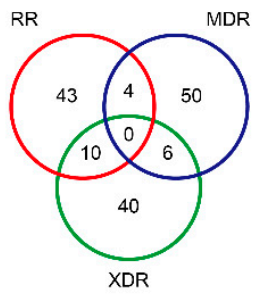

E

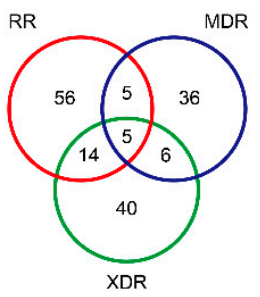

Figure 1. Up and down-regulated proteins between DS and DR strains. (A-C) Hierarchical clustering of proteins differentially expressed in the RR vs. DS strains (A), the MDR vs. DS strains (B), and the XDR vs. DS strains (C). Log2 ratios were calculated based on LFQ intensity. (D,E) Venn diagram showed the number of up-regulated (D) or downregulated (E) proteins in any of the RR, MDR, XDR strains, when compared to the DS strain. RR, rifampin-resistant; MDR, multidrug-resistant; XDR, extensively drug-resistant; DS, drug-sensitive; LFQ, label-free quantitation.

Importantly, both RR and MDR strains showed a high expression of 4 proteins: iniC, Rv2141c, folB, and Rv2561 (Figure 1D). In addition, 10 proteins were increased in the RR and XDR strains, while 6 proteins were increased in the MDR and XDR strains (Figure 1D). However, no protein was found up-regulated in all 3 drug-resistant strains. Functional profiles of the overlapped up-regulated genes were shown in Table 1. The majority of them were involved in intermediary metabolism and respiration. Additionally, 5, 14, and 6 proteins were decreased in the RR \& MDR, RR \& XDR, and MDR \& XDR strains, respectively (Figure 1E). More importantly, the RR, MDR, and XDR strains all showed low expression of 5 proteins: fadE9, espB, espL, esxK, and Rv3175 (Figure 1E). Among them, espB, espL, and esxK were involved in cell wall and cell processes. fadE9 and Rv3175 were involved in lipid metabolism and intermediary metabolism and respiration, respectively (Table 2).

Table 1. Up-regulated genes in the DR strains compared to the DS strain, sorted in order of gene number.

\begin{tabular}{|c|c|c|c|c|c|}
\hline $\begin{array}{l}\text { Locus } \\
\text { Tag. }\end{array}$ & $\begin{array}{c}\text { Gene } \\
\text { Symbol }\end{array}$ & Function & Product & $\begin{array}{c}\text { Functional } \\
\text { Category }\end{array}$ & Strains \\
\hline Rv0343 & iniC & Unknown & $\begin{array}{c}\text { Isoniazid } \\
\text { inductible gene } \\
\text { protein IniC }\end{array}$ & $\begin{array}{l}\text { cell wall and cell } \\
\text { processes }\end{array}$ & RR and MDR \\
\hline Rv0408 & pta & $\begin{array}{l}\text { Involved at the last step (of two) in the } \\
\text { conversion of acetate to acetyl-CoA } \\
\text { [catalytic activity: acetyl-CoA + } \\
\text { phosphate = CoA + acetyl phosphate] }\end{array}$ & $\begin{array}{l}\text { Probable } \\
\text { phosphate } \\
\text { acetyltransferase } \\
\text { Pta (phospho- } \\
\text { transacetylase) }\end{array}$ & $\begin{array}{l}\text { intermediary } \\
\text { metabolism and } \\
\text { respiration }\end{array}$ & RR and XDR \\
\hline Rv0593 & lprL & $\begin{array}{l}\text { Unknown, but thought to be involved in } \\
\text { host cell invasion. }\end{array}$ & $\begin{array}{c}\text { Possible } \\
\text { Mce-family } \\
\text { lipoprotein LprL } \\
\text { (Mce-family } \\
\text { lipoprotein Mce2E) }\end{array}$ & $\begin{array}{l}\text { cell wall and cell } \\
\text { processes }\end{array}$ & RR and XDR \\
\hline
\end{tabular}


Table 1. Cont.

\begin{tabular}{|c|c|c|c|c|c|}
\hline $\begin{array}{l}\text { Locus } \\
\text { Tag. }\end{array}$ & $\begin{array}{c}\text { Gene } \\
\text { Symbol }\end{array}$ & Function & Product & $\begin{array}{l}\text { Functional } \\
\text { Category }\end{array}$ & Strains \\
\hline Rv0652 & rplL & $\begin{array}{l}\text { Involved in translation mechanisms: } \\
\text { seems to be the binding site for several of } \\
\text { the factors involved in protein synthesis } \\
\text { and appears to be essential for accurate } \\
\text { translation. }\end{array}$ & $\begin{array}{l}50 S \text { ribosomal } \\
\text { protein L7/L12 } \\
\text { RplL (SA1) }\end{array}$ & $\begin{array}{l}\text { information } \\
\text { pathways }\end{array}$ & RR and XDR \\
\hline Rv1185c & fadD21 & $\begin{array}{l}\text { Function unknown but supposedly } \\
\text { involved in lipid degradation. }\end{array}$ & $\begin{array}{c}\text { Probable } \\
\text { fatty-acid-AMP } \\
\text { ligase FadD21 } \\
\text { (fatty-acid-AMP } \\
\text { synthetase) } \\
\text { (fatty-acid-AMP } \\
\text { synthase) }\end{array}$ & lipid metabolism & RR and XDR \\
\hline Rv1187 & $\operatorname{roc} A$ & $\begin{array}{l}\text { Involved in the arginase pathway } \\
\text { [catalytic activity: } \\
\text { 1-pyrroline-5-carboxylate + NAD }(+)+ \\
\mathrm{H}(2) \mathrm{O}=\text { L-glutamate + NADH] }\end{array}$ & $\begin{array}{l}\text { Probable pyrroline- } \\
\text { 5-carboxylate } \\
\text { dehydrogenase } \\
\text { RocA }\end{array}$ & $\begin{array}{l}\text { intermediary } \\
\text { metabolism and } \\
\text { respiration }\end{array}$ & $\begin{array}{l}\text { MDR and } \\
\text { XDR }\end{array}$ \\
\hline Rv1416 & $\mathrm{ribH}$ & $\begin{array}{l}\text { Riboflavin synthase is a bifunctional } \\
\text { enzyme complex involved in riboflavin } \\
\text { synthesis. Riboflavin synthase catalyzes } \\
\text { the formation of riboflavin from } \\
\text { 5-amino-6-(1'-D)-ribityl-amino- } \\
\text { 2,4(1H,3H)-pyrimidinedione and } \\
\text { L-3,4-dihydrohy-2-butanone-4- } \\
\text { phosphate via 6,7-dimethyl-8-lumazine. } \\
\text { The beta subunit catalyzes the } \\
\text { condensation of 5-amino-6-(1'-D)-ribityl- } \\
\text { amino-2,4(1H,3H)-pyrimidinedione with } \\
\text { L-3,4-dihydrohy-2-butanone-4- } \\
\text { phosphate yielding } \\
\text { 6,7-dimethyl-8-lumazine }\end{array}$ & $\begin{array}{l}\text { Probable riboflavin } \\
\text { synthase beta } \\
\text { chain RibH } \\
\text { (6,7-dimethyl-8- } \\
\text { ribityllumazine } \\
\text { synthase) (DMRL } \\
\text { synthase) } \\
\text { (lumazine } \\
\text { synthase) }\end{array}$ & $\begin{array}{l}\text { intermediary } \\
\text { metabolism and } \\
\text { respiration }\end{array}$ & RR and XDR \\
\hline
\end{tabular}

Involved in propionic acid fermentation.

Catalyzes the isomerization of succinyl-CoA to methylmalonyl-CoA

Rv1493 mutB during synthesis of propionate from tricarboxylic acid-cycle intermediates [catalytic activity:

(R)-2-methyl-3-oxopropanoyl-CoA = succinyl-CoA]

\begin{tabular}{|c|c|c|c|c|c|}
\hline Rv1711 & Rv1711 & Function unknown & $\begin{array}{l}\text { Conserved } \\
\text { hypothetical } \\
\text { protein }\end{array}$ & $\begin{array}{c}\text { Conserved } \\
\text { hypotheticals }\end{array}$ & RR and XDR \\
\hline Rv1780 & Rv1780 & Function unknown & Conserved protein & $\begin{array}{c}\text { Conserved } \\
\text { hypotheticals }\end{array}$ & RR and XDR \\
\hline Rv2115c & mpa & $\begin{array}{c}\text { Involved in proteasomal protein } \\
\text { degradation }\end{array}$ & $\begin{array}{l}\text { Mycobacterial } \\
\text { proteasome } \\
\text { ATPase Mpa }\end{array}$ & $\begin{array}{l}\text { cell wall and cell } \\
\text { processes }\end{array}$ & $\begin{array}{l}\text { MDR and } \\
\text { XDR }\end{array}$ \\
\hline Rv2141c & Rv2141c & Unknown & Conserved protein & $\begin{array}{l}\text { intermediary } \\
\text { metabolism and } \\
\text { respiration }\end{array}$ & RR and MDR \\
\hline $\mathrm{Rv} 2148 \mathrm{c}$ & Rv2148c & Unknown & Conserved protein & $\begin{array}{c}\text { Conserved } \\
\text { hypotheticals }\end{array}$ & RR and XDR \\
\hline
\end{tabular}

Probable methylmalonyl-

CoA mutase large lipid metabolism RR and XDR subunit MutB

(MCM) 
Table 1. Cont.

\begin{tabular}{|c|c|c|c|c|c|}
\hline $\begin{array}{l}\text { Locus } \\
\text { Tag. }\end{array}$ & $\begin{array}{c}\text { Gene } \\
\text { Symbol }\end{array}$ & Function & Product & $\begin{array}{l}\text { Functional } \\
\text { Category }\end{array}$ & Strains \\
\hline Rv2272 & Rv2272 & Unknown & $\begin{array}{c}\text { Probable } \\
\text { conserved } \\
\text { transmembrane } \\
\text { protein }\end{array}$ & $\begin{array}{l}\text { cell wall and cell } \\
\text { processes }\end{array}$ & $\begin{array}{l}\text { MDR and } \\
\text { XDR }\end{array}$ \\
\hline Rv2561 & Rv2561 & Function unknown & $\begin{array}{l}\text { Conserved } \\
\text { hypothetical } \\
\text { protein }\end{array}$ & $\begin{array}{c}\text { Conserved } \\
\text { hypotheticals }\end{array}$ & RR and MDR \\
\hline Rv2851c & Rv2851c & Acetylation, substrate unknown & $\begin{array}{l}\text { GCN5-related N- } \\
\text { acetyltransferase }\end{array}$ & $\begin{array}{l}\text { intermediary } \\
\text { metabolism and } \\
\text { respiration }\end{array}$ & RR and XDR \\
\hline Rv3244c & lpqB & Unknown & $\begin{array}{c}\text { Probable } \\
\text { conserved } \\
\text { lipoprotein LpqB }\end{array}$ & $\begin{array}{l}\text { cell wall and cell } \\
\text { processes }\end{array}$ & $\begin{array}{l}\text { MDR and } \\
\text { XDR }\end{array}$ \\
\hline Rv3371 & Rv3371 & $\begin{array}{l}\text { May be involved in synthesis of } \\
\text { triacylglycerol }\end{array}$ & $\begin{array}{c}\text { Possible } \\
\text { triacylglycerol } \\
\text { synthase } \\
\text { (diacylglycerol } \\
\text { acyltransferase) }\end{array}$ & lipid metabolism & $\begin{array}{l}\text { MDR and } \\
\text { XDR }\end{array}$ \\
\hline Rv3606c & folK & $\begin{array}{l}\text { Involved in dihydrofolate biosynthesis } \\
\text { (at the first step) [catalytic activity: ATP + } \\
\text { 2-amino-4-hydroxy-6-hydroxymethyl- } \\
\text { 7,8-dihydropteridine = AMP + } \\
\text { 2-amino-7,8-dihydro-4-hydroxy-6- } \\
\text { (diphosphooxymethyl)pteridine] }\end{array}$ & $\begin{array}{l}\text { 2-amino-4- } \\
\text { hydroxy-6- } \\
\text { hydroxy- } \\
\text { methyldihy- } \\
\text { dropteridine } \\
\text { pyrophosphoki- } \\
\text { nase FolK } \\
\text { (7,8-dihydro-6- } \\
\text { hydroxy- } \\
\text { methylpterin- } \\
\text { pyrophosphokinase) } \\
\text { (HPPK) } \\
\text { (6-hydroxymethyl- } \\
\text { 7,8-dihydropterin } \\
\text { pyrophosphoki- } \\
\text { nase) (PPPK) } \\
\text { (2-amino-4- } \\
\text { hydroxy-6- } \\
\text { hydroxymethyldihy- } \\
\text { dropteridine } \\
\text { diphosphokinase) } \\
\text { (7,8-dihydro-6- } \\
\text { hydroxymethylpterin- } \\
\text { diphosphokinase) } \\
\text { (6-hydroxymethyl- } \\
\text { 7,8-dihydropterin } \\
\text { diphosphokinase) }\end{array}$ & $\begin{array}{l}\text { intermediary } \\
\text { metabolism and } \\
\text { respiration }\end{array}$ & $\begin{array}{l}\text { MDR and } \\
\text { XDR }\end{array}$ \\
\hline Rv3607c & folB & $\begin{array}{c}\text { Involved in folate biosynthesis. Catalyzes } \\
\text { the conversion of 7,8-dihydroneopterin } \\
\text { to 6-hydroxymethyl-7,8-dihydropterin } \\
\text { [catalytic activity: } \\
\text { 2-amino-4-hydroxy-6-(D-erythro-1,2,3- } \\
\text { trihydroxypropyl)-7,8-dihydropteridine } \\
\text { = 2-amino-4-hydroxy-6-hydroxymethyl- } \\
\text { 7,8-dihydropteridine + } \\
\text { glycolaldehyde] }\end{array}$ & $\begin{array}{c}\text { Probable } \\
\text { dihydroneopterin } \\
\text { aldolase FolB } \\
\text { (DHNA) }\end{array}$ & $\begin{array}{l}\text { intermediary } \\
\text { metabolism and } \\
\text { respiration }\end{array}$ & RR and MDR \\
\hline
\end{tabular}


Table 2. Down-regulated genes in the DR strains compared to the DS strain, sorted in order of gene number.

\begin{tabular}{|c|c|c|c|c|c|}
\hline $\begin{array}{l}\text { Locus } \\
\text { Tag }\end{array}$ & $\begin{array}{l}\text { Gene } \\
\text { Symbol }\end{array}$ & Function & Product & $\begin{array}{l}\text { Functional } \\
\text { Category }\end{array}$ & Strains \\
\hline Rv0077c & Rv0077c & $\begin{array}{c}\text { Function unknown; probably } \\
\text { involved in cellular } \\
\text { metabolism. }\end{array}$ & Probable oxidoreductase & $\begin{array}{l}\text { Intermediary } \\
\text { metabolism and } \\
\text { respiration }\end{array}$ & RR and XDR \\
\hline Rv0105c & rpmB & $\begin{array}{l}\text { Possibly involved in a } \\
\text { translation mechanism }\end{array}$ & $\begin{array}{l}\text { 50S ribosomal protein L28-1 } \\
\text { RpmB1 }\end{array}$ & $\begin{array}{l}\text { Information } \\
\text { pathways }\end{array}$ & RR and MDR \\
\hline Rv0282 & eccA3 & Unknown & $\begin{array}{l}\text { ESX conserved component } \\
\text { EccA3. ESX-3 type VII secretion } \\
\text { system protein. }\end{array}$ & $\begin{array}{l}\text { Cell wall and cell } \\
\text { processes }\end{array}$ & RR and XDR \\
\hline Rv0283 & eccB3 & Unknown & $\begin{array}{l}\text { ESX conserved component } \\
\text { EccB3. ESX-3 type VII secretion } \\
\text { system protein. Possible } \\
\text { membrane protein. }\end{array}$ & $\begin{array}{l}\text { Cell wall and cell } \\
\text { processes }\end{array}$ & RR and XDR \\
\hline Rv0752c & fadE9 & $\begin{array}{c}\text { Function unknown, but } \\
\text { involved in lipid degradation. }\end{array}$ & $\begin{array}{c}\text { Probable acyl-CoA } \\
\text { dehydrogenase FadE9 }\end{array}$ & lipid metabolism & $\begin{array}{l}\text { RR, MDR } \\
\text { and XDR }\end{array}$ \\
\hline Rv0753c & mmsA & $\begin{array}{l}\text { Plays a role in valine and } \\
\text { pyrimidine metabolism }\end{array}$ & $\begin{array}{c}\text { Probable } \\
\text { methylmalonate-semialdehyde } \\
\text { dehydrogenase }\end{array}$ & $\begin{array}{l}\text { Intermediary } \\
\text { metabolism and } \\
\text { respiration }\end{array}$ & RR and XDR \\
\hline
\end{tabular}

Metal cation-transporting

Rv0969 ctpV $\quad \begin{aligned} & \text { ATPase; possibly catalyzes the } \\ & \text { transport of an undetermined }\end{aligned}$
metal cation with the hydrolysis of ATP

\begin{tabular}{|c|c|c|c|c|c|}
\hline Rv1196 & PPE18 & Unknown & PPE family protein PPE18 & $\mathrm{PE} / \mathrm{PPE}$ & $\begin{array}{l}\text { MDR and } \\
\text { XDR }\end{array}$ \\
\hline Rv1197 & esxK & Function unknown & $\begin{array}{l}\text { ESAT-6 like protein EsxK } \\
\text { (ESAT-6 like protein 3) }\end{array}$ & $\begin{array}{l}\text { Cell wall and cell } \\
\text { processes }\end{array}$ & $\begin{array}{l}\text { RR, MDR } \\
\text { and XDR }\end{array}$ \\
\hline Rv1198 & esxL & Function unknown & $\begin{array}{l}\text { Putative ESAT-6 like protein } \\
\text { EsxL (ESAT-6 like protein 4) }\end{array}$ & $\begin{array}{l}\text { Cell wall and cell } \\
\text { processes }\end{array}$ & $\mathrm{RR}$ and MDR \\
\hline Rv1793 & esxN & Function unknown & $\begin{array}{l}\text { Putative ESAT-6 like protein } \\
\text { EsxN (ESAT-6 like protein 5) }\end{array}$ & $\begin{array}{l}\text { Cell wall and cell } \\
\text { processes }\end{array}$ & $\mathrm{RR}$ and MDR \\
\hline Rv1932 & $\operatorname{tpx}$ & $\begin{array}{l}\text { Has antioxidant activity. } \\
\text { Could remove peroxides or } \\
\mathrm{H}(2) \mathrm{O}(2)\end{array}$ & Probable thiol peroxidase Tpx & $\begin{array}{l}\text { Virulence, } \\
\text { detoxification, } \\
\text { adaptation }\end{array}$ & $\begin{array}{l}\text { MDR and } \\
\text { XDR }\end{array}$ \\
\hline Rv1980c & mpt64 & Unknown & $\begin{array}{l}\text { Immunogenic protein Mpt64 } \\
\text { (antigen Mpt64/MPB64) }\end{array}$ & $\begin{array}{l}\text { Cell wall and cell } \\
\text { processes }\end{array}$ & $\begin{array}{l}\text { MDR and } \\
\text { XDR }\end{array}$ \\
\hline Rv2094c & tatA & Involved in protein export: & $\begin{array}{l}\text { Sec-independent protein } \\
\text { translocase membrane-bound } \\
\text { protein TatA }\end{array}$ & $\begin{array}{l}\text { Cell wall and cell } \\
\text { processes }\end{array}$ & RR and XDR \\
\hline Rv2108 & PPE36 & Unknown & PPE family protein PPE36 & $\mathrm{PE} / \mathrm{PPE}$ & $\begin{array}{l}\text { MDR and } \\
\text { XDR }\end{array}$ \\
\hline Rv2284 & lipM & $\begin{array}{l}\text { Hydrolysis of lipids (bound } \\
\text { ester). }\end{array}$ & Probable esterase LipM & $\begin{array}{l}\text { Intermediary } \\
\text { metabolism and } \\
\text { respiration }\end{array}$ & RR and XDR \\
\hline Rv2428 & ahpC & $\begin{array}{l}\text { Involved in oxidative stress } \\
\text { response }\end{array}$ & $\begin{array}{c}\text { Alkyl hydroperoxide reductase } \\
\text { C protein AhpC (alkyl } \\
\text { hydroperoxidase C) }\end{array}$ & $\begin{array}{l}\text { Virulence, } \\
\text { detoxification, } \\
\text { adaptation }\end{array}$ & $\mathrm{RR}$ and MDR \\
\hline Rv2945c & $\operatorname{lpp} X$ & Unknown & $\begin{array}{l}\text { Probable conserved lipoprotein } \\
\text { LppX }\end{array}$ & $\begin{array}{l}\text { Cell wall and cell } \\
\text { processes }\end{array}$ & RR and XDR \\
\hline
\end{tabular}
transporter P-type ATPase CtpV
Probable metal cation
Cell wall and cell processes

RR and XDR 
Table 2. Cont.

\begin{tabular}{|c|c|c|c|c|c|}
\hline $\begin{array}{l}\text { Locus } \\
\text { Tag }\end{array}$ & $\begin{array}{c}\text { Gene } \\
\text { Symbol }\end{array}$ & Function & Product & $\begin{array}{l}\text { Functional } \\
\text { Category }\end{array}$ & Strains \\
\hline Rv3174 & Rv3174 & $\begin{array}{l}\text { Function unknown; involved } \\
\text { in cellular metabolism. }\end{array}$ & $\begin{array}{c}\text { Probable short-chain } \\
\text { dehydrogenase/reductase }\end{array}$ & $\begin{array}{l}\text { Intermediary } \\
\text { metabolism and } \\
\text { respiration }\end{array}$ & RR and XDR \\
\hline Rv3175 & Rv3175 & $\begin{array}{l}\text { Function unknown; involved } \\
\text { in cellular metabolism. }\end{array}$ & $\begin{array}{l}\text { Possible amidase } \\
\text { (aminohydrolase) }\end{array}$ & $\begin{array}{l}\text { intermediary } \\
\text { metabolism and } \\
\text { respiration }\end{array}$ & $\begin{array}{l}\text { RR, MDR } \\
\text { and XDR }\end{array}$ \\
\hline Rv3275c & purE & $\begin{array}{l}\text { Involved in purine } \\
\text { biosynthesis (sixth step). }\end{array}$ & $\begin{array}{l}\text { Probable phosphoribosy- } \\
\text { laminoimidazole carboxylase } \\
\text { catalytic subunit PurE (air } \\
\text { carboxylase) (AIRC) }\end{array}$ & $\begin{array}{l}\text { Intermediary } \\
\text { metabolism and } \\
\text { respiration }\end{array}$ & RR and XDR \\
\hline Rv3284 & Rv3284 & Function unknown & Conserved hypothetical protein & $\begin{array}{c}\text { Conserved } \\
\text { hypotheticals }\end{array}$ & RR and XDR \\
\hline Rv3288c & usfY & Function unknown & Putative protein UsfY & $\begin{array}{c}\text { Conserved } \\
\text { hypotheticals }\end{array}$ & RR and XDR \\
\hline Rv3295 & Rv3295 & $\begin{array}{l}\text { Involved in transcriptional } \\
\text { mechanism }\end{array}$ & $\begin{array}{l}\text { Probable transcriptional } \\
\text { regulatory protein (probably } \\
\text { TetR-family) }\end{array}$ & $\begin{array}{l}\text { Regulatory } \\
\text { proteins }\end{array}$ & RR and XDR \\
\hline Rv3311 & Rv3311 & Function unknown & Conserved protein & $\begin{array}{c}\text { Conserved } \\
\text { hypotheticals }\end{array}$ & RR and XDR \\
\hline Rv3327 & Rv3327 & $\begin{array}{c}\text { Involved in the transposition } \\
\text { in the insertion sequence } \\
\text { element IS1547. }\end{array}$ & $\begin{array}{l}\text { Probable transposase fusion } \\
\text { protein }\end{array}$ & $\begin{array}{l}\text { Insertion seqs and } \\
\text { phages }\end{array}$ & RR and MDR \\
\hline Rv3874 & esxB & $\begin{array}{l}\text { Unknown. Exported protein } \\
\text { cotranscribed with } \\
\text { Rv3875 I MT3989 I MTV027.10. }\end{array}$ & $\begin{array}{l}10 \mathrm{kDa} \text { culture filtrate antigen } \\
\text { EsxB (LHP) (CFP10) }\end{array}$ & $\begin{array}{l}\text { Cell wall and cell } \\
\text { processes }\end{array}$ & $\begin{array}{l}\text { MDR and } \\
\text { XDR }\end{array}$ \\
\hline Rv3875 & esxA & $\begin{array}{l}\text { Unknown. Elicits high level of } \\
\text { inf-gamma from memory } \\
\text { effector cells during }\end{array}$ & $\begin{array}{c}6 \mathrm{kDa} \text { early secretory antigenic } \\
\text { target EsxA (ESAT-6) }\end{array}$ & $\begin{array}{l}\text { Cell wall and cell } \\
\text { processes }\end{array}$ & $\begin{array}{l}\text { MDR and } \\
\text { XDR }\end{array}$ \\
\hline Rv3880c & espL & Function unknown & $\begin{array}{l}\text { ESX-1 secretion-associated } \\
\text { protein EspL }\end{array}$ & $\begin{array}{l}\text { Cell wall and cell } \\
\text { processes }\end{array}$ & $\begin{array}{l}\text { RR, MDR } \\
\text { and XDR }\end{array}$ \\
\hline Rv3881c & espB & $\begin{array}{l}\text { Function unknown. Is a } \\
\text { proteolytic substrate of } \\
\text { MYCP1 | Rv3883c. }\end{array}$ & $\begin{array}{l}\text { Secreted ESX-1 substrate } \\
\text { protein B, EspB. Conserved } \\
\text { alanine and glycine rich protein }\end{array}$ & $\begin{array}{l}\text { Cell wall and cell } \\
\text { processes }\end{array}$ & $\begin{array}{l}\text { RR, MDR } \\
\text { and XDR }\end{array}$ \\
\hline
\end{tabular}

\subsection{Specifically Expressed and Not Detected Proteins in the RR, $M D R, X D R$, and DS Strains}

A total of 87 proteins were identified specifically expressed in any DR strains compared to the DS strain. Among them, 54 were specifically expressed in the RR strain, 16 in the MDR strain, and 33 in the XDR strain (Figure 2A). Importantly, 5 proteins Rv2630, mce2C, moaX, truA, and Rv0200, were especially expressed in the RR and MDR strains. Two proteins, Rv1363c and Rv1360, were especially expressed in the RR and XDR strains. NadB was especially expressed in the MDR and XDR strains. More importantly, 4 proteins were specifically expressed in all 3 DR strains: lprF, mce2R, mce2B, and Rv2627c. Among them, lprF was involved in the cell wall and cell processes, while mce2B was involved in host cell invasion. In addition, mce2R and Rv2627c were regulatory and conserved proteins, respectively (Table 3 ). 
A

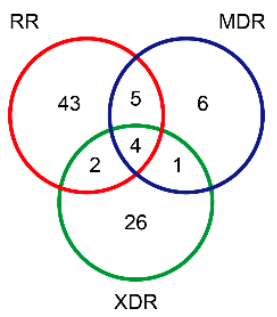

B

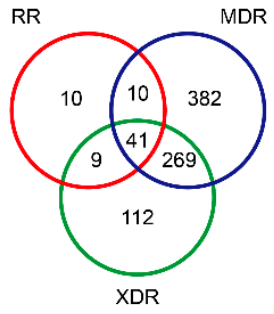

C

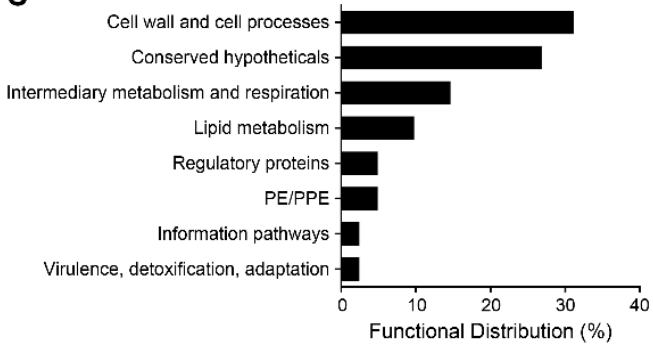

Figure 2. Specifically expressed and not detected proteins between DS and DR strains. (A,B) Venn diagrams showed the number of proteins specifically expressed (A) and not detected (B) in any of the RR, MDR, and XDR strains. (C) Functional distribution of the 41 not detected proteins in all 3 DR strains according to the TubercuList Functional Category (http: //svitsrv8.epfl.ch/tuberculist/ accessed on 18 February 2021). RR, rifampin-resistant; MDR, multidrug-resistant; XDR, extensively drug-resistant; DS, drug-sensitive; PE, proline-glutamic acid; and PPE, proline-proline-glutamic acid.

Table 3. Specifically expressed genes in the DR strains compared to the DS strain, sorted in order of gene number.

\begin{tabular}{|c|c|c|c|c|c|}
\hline $\begin{array}{l}\text { Locus } \\
\text { Tag }\end{array}$ & $\begin{array}{l}\text { Gene } \\
\text { Symbol }\end{array}$ & Function & Product & $\begin{array}{l}\text { Functional } \\
\text { Category }\end{array}$ & Strains \\
\hline Rv0200 & Rv0200 & Unknown & $\begin{array}{l}\text { Possible conserved } \\
\text { transmembrane protein }\end{array}$ & $\begin{array}{l}\text { Cell wall and cell } \\
\text { processes }\end{array}$ & $\mathrm{RR}$ and MDR \\
\hline Rv0586 & mce2R & $\begin{array}{l}\text { Involved in transcriptional } \\
\text { mechanism. }\end{array}$ & $\begin{array}{c}\text { Probable transcriptional } \\
\text { regulatory protein Mce2R } \\
\text { (GntR-family) }\end{array}$ & $\begin{array}{l}\text { Regulatory } \\
\text { proteins }\end{array}$ & $\begin{array}{l}\text { RR, MDR, } \\
\text { and XDR }\end{array}$ \\
\hline Rv0590 & mce2B & $\begin{array}{l}\text { Unknown, but thought to be } \\
\text { involved in host cell invasion. }\end{array}$ & Mce-family protein Mce2B & $\begin{array}{l}\text { Virulence, } \\
\text { detoxification, } \\
\text { adaptation }\end{array}$ & $\begin{array}{l}\text { RR, MDR, } \\
\text { and XDR }\end{array}$ \\
\hline Rv0591 & mce2C & $\begin{array}{l}\text { Unknown, but thought to be } \\
\text { involved in host cell invasion }\end{array}$ & Mce-family protein Mce2C & $\begin{array}{l}\text { Virulence, } \\
\text { detoxification, } \\
\text { adaptation }\end{array}$ & $\mathrm{RR}$ and $\mathrm{MDR}$ \\
\hline Rv1360 & Rv1360 & $\begin{array}{c}\text { Function unknown; probably } \\
\text { involved in cellular } \\
\text { metabolism }\end{array}$ & Probable oxidoreductase & $\begin{array}{l}\text { Intermediary } \\
\text { metabolism and } \\
\text { respiration }\end{array}$ & RR and XDR \\
\hline Rv1363c & Rv1363c & Function unknown & Possible membrane protein & $\begin{array}{l}\text { Cell wall and cell } \\
\text { processes }\end{array}$ & RR and XDR \\
\hline Rv1368 & $\operatorname{lprF}$ & Unknown & $\begin{array}{l}\text { Probable conserved } \\
\text { lipoprotein LprF }\end{array}$ & $\begin{array}{l}\text { Cell wall and cell } \\
\text { processes }\end{array}$ & $\begin{array}{l}\text { RR, MDR, } \\
\text { and XDR }\end{array}$ \\
\hline Rv1595 & NadB & Quinolinate biosynthesis & $\begin{array}{l}\text { Probable L-aspartate oxidase } \\
\text { NadB }\end{array}$ & $\begin{array}{l}\text { Intermediary } \\
\text { metabolism and } \\
\text { respiration }\end{array}$ & $\begin{array}{l}\text { MDR and } \\
\text { XDR }\end{array}$ \\
\hline Rv2627c & Rv2627c & Function unknown & Conserved protein & $\begin{array}{c}\text { Conserved } \\
\text { hypotheticals }\end{array}$ & $\begin{array}{l}\text { RR, MDR, } \\
\text { and XDR }\end{array}$ \\
\hline Rv2630 & $\operatorname{Rv} 2630$ & Unknown & Hypothetical protein & $\begin{array}{c}\text { Conserved } \\
\text { hypotheticals }\end{array}$ & RR and MDR \\
\hline Rv3323c & $\operatorname{moax}$ & $\begin{array}{l}\text { Thought to be involved in } \\
\text { molybdenum cofactor } \\
\text { biosynthesis. }\end{array}$ & $\begin{array}{l}\text { Probable MoaD-MoaE fusion } \\
\text { protein MoaX }\end{array}$ & $\begin{array}{l}\text { Intermediary } \\
\text { metabolism and } \\
\text { respiration }\end{array}$ & RR and MDR \\
\hline Rv3455c & $\operatorname{truA}$ & $\begin{array}{l}\text { Formation of pseudouridine } \\
\text { at positions } 38-40 \text { in the } \\
\text { anticodon stem and loop of } \\
\text { transfer RNAS }\end{array}$ & $\begin{array}{c}\text { Probable tRNA } \\
\text { pseudouridine synthase a } \\
\text { TruA }\end{array}$ & $\begin{array}{l}\text { Information } \\
\text { pathways }\end{array}$ & $\mathrm{RR}$ and $\mathrm{MDR}$ \\
\hline
\end{tabular}

In addition, 833 proteins were not detected in the DR strains when compared to the DS strain. Among them, 70 proteins were not identified in the RR strain, 702 in the MDR 
strain, and 431 in the XDR strain (Figure 2B). Importantly, 10, 9, and 269 proteins were not observed in the RR and MDR strains, the RR and XDR strains, and the MDR and XDR strains, respectively. More importantly, all 3 DR strains did not express 41 proteins. The majority of them were involved in cell wall and cell processes (Figure 2C). Functional classification of these undetected proteins in all 3 DR strains is shown in (Table 4).

Table 4. Undetected genes in all 3 DR strains compared to the DS strain, sorted in order of gene number.

\begin{tabular}{|c|c|c|c|c|}
\hline Locus Tag & $\begin{array}{c}\text { Gene } \\
\text { Symbol }\end{array}$ & Function & Product & $\begin{array}{l}\text { Functional } \\
\text { Category }\end{array}$ \\
\hline Rv0028 & Rv0028 & Unknown & $\begin{array}{l}\text { Unknown conserved } \\
\text { hypothetical protein }\end{array}$ & $\begin{array}{c}\text { Conserved } \\
\text { hypotheticals }\end{array}$ \\
\hline Rv0103c & $\operatorname{ctp} B$ & $\begin{array}{l}\text { Cation-transporting ATPase; possibly } \\
\text { catalyzes the transport of a cation (possibly } \\
\text { copper) with the hydrolyze of ATP }\end{array}$ & $\begin{array}{l}\text { Probable cation-transporter } \\
\text { P-type ATPase B CtpB }\end{array}$ & $\begin{array}{l}\text { Cell wall and cell } \\
\text { processes }\end{array}$ \\
\hline Rv0145 & Rv0146 & Possible methyltransferase & $\begin{array}{l}\text { Possible S-adenosyl } \\
\text { methionine-dependent } \\
\text { methyltransferase }\end{array}$ & Lipid metabolism \\
\hline Rv0203 & Rv0203 & Unknown & PoctpBssible exported protein & $\begin{array}{l}\text { Cell wall and cell } \\
\text { processes }\end{array}$ \\
\hline $\mathrm{Rv} 0275 c$ & Rv0275c & $\begin{array}{l}\text { Could be involved in transcriptional } \\
\text { mechanism }\end{array}$ & $\begin{array}{l}\text { Possible transcriptional } \\
\text { regulatory protein (possibly } \\
\text { TetR-family) }\end{array}$ & Regulatory proteins \\
\hline Rv0402c & mmpL1 & $\begin{array}{l}\text { Unknown. Thought to be involved in fatty } \\
\text { acid transport }\end{array}$ & $\begin{array}{c}\text { Probable conserved } \\
\text { transmembrane transport } \\
\text { protein MmpL1 }\end{array}$ & $\begin{array}{l}\text { Cell wall and cell } \\
\text { processes }\end{array}$ \\
\hline Rv0677c & mmpS5 & Unknown & $\begin{array}{l}\text { Possible conserved membrane } \\
\text { protein MmpS5 }\end{array}$ & $\begin{array}{l}\text { Cell wall and cell } \\
\text { processes }\end{array}$ \\
\hline Rv0855 & far & $\begin{array}{l}\text { Function unknown, but involvement in } \\
\text { lipid degradation (racemization) }\end{array}$ & $\begin{array}{l}\text { Probable fatty-acid-CoA } \\
\text { racemase Far }\end{array}$ & Lipid metabolism \\
\hline Rv1189 & $\operatorname{sigI}$ & $\begin{array}{l}\text { The sigma factor is an initiation factor that } \\
\text { promotes attachment of the RNA } \\
\text { polymerase to specific initiation sites and } \\
\text { then is released }\end{array}$ & $\begin{array}{c}\text { Possible alternative RNA } \\
\text { polymerase sigma factor SigI }\end{array}$ & $\begin{array}{l}\text { Information } \\
\text { pathways }\end{array}$ \\
\hline Rv1287 & Rv1287 & Unknown & Conserved hypothetical protein & $\begin{array}{c}\text { Conserved } \\
\text { hypotheticals }\end{array}$ \\
\hline Rv1290c & Rv1290c & $\begin{array}{l}\text { Function unknown. Thought to be involved } \\
\text { in virulence }\end{array}$ & Conserved protein & $\begin{array}{c}\text { Conserved } \\
\text { hypotheticals }\end{array}$ \\
\hline Rv1405c & Rv1405c & Causes methylation & Putative methyltransferase & $\begin{array}{l}\text { Intermediary } \\
\text { metabolism and } \\
\text { respiration }\end{array}$ \\
\hline Rv1424c & Rv1424c & Unknown & Possible membrane protein & $\begin{array}{l}\text { Cell wall and cell } \\
\text { processes }\end{array}$ \\
\hline Rv1774 & Rv1774 & $\begin{array}{l}\text { Function unknown; probably involved in } \\
\text { cellular metabolism }\end{array}$ & Probable oxidoreductase & $\begin{array}{l}\text { Intermediary } \\
\text { metabolism and } \\
\text { respiration }\end{array}$ \\
\hline Rv1841c & Rv1841c & Unknown & $\begin{array}{l}\text { Conserved hypothetical } \\
\text { membrane protein }\end{array}$ & $\begin{array}{l}\text { Cell wall and cell } \\
\text { processes }\end{array}$ \\
\hline Rv1976c & Rv1976c & Unknown & Conserved hypothetical protein & $\begin{array}{c}\text { Conserved } \\
\text { hypotheticals }\end{array}$ \\
\hline Rv2116 & lppK & Unknown & onserved lipoprotein LppK & $\begin{array}{l}\text { Cell wall and cell } \\
\text { processes }\end{array}$ \\
\hline
\end{tabular}


Table 4. Cont.

\begin{tabular}{|c|c|c|c|c|}
\hline Locus Tag & $\begin{array}{c}\text { Gene } \\
\text { Symbol }\end{array}$ & Function & Product & $\begin{array}{l}\text { Functional } \\
\text { Category }\end{array}$ \\
\hline Rv2219A & Rv2219A & Unknown & $\begin{array}{l}\text { Probable conserved membrane } \\
\text { protein }\end{array}$ & $\begin{array}{l}\text { Cell wall and cell } \\
\text { processes }\end{array}$ \\
\hline Rv2370c & Rv2370c & Unknown & Conserved hypothetical protein & $\begin{array}{c}\text { Conserved } \\
\text { hypotheticals }\end{array}$ \\
\hline
\end{tabular}

\begin{tabular}{|c|c|c|c|c|}
\hline Rv2383c & $\mathrm{mbtB}$ & $\begin{array}{l}\text { Involved in the biogenesis of the } \\
\text { hydroxyphenyloxazoline-containing } \\
\text { siderophore mycobactins. This peptide } \\
\text { synthase forms amide bond between the } \\
\text { carboxylic acid of salicylate and the } \\
\text { alpha-amino group of serine } \\
\text { (serine/threonine ligation). }\end{array}$ & $\begin{array}{l}\text { Phenyloxazolinesynthase MbtB } \\
\text { (phenyloxazoline synthetase) }\end{array}$ & Lipid metabolism \\
\hline Rv2440c & obg & Essential GTP-binding protein & $\begin{array}{l}\text { Probable GTP1/Obg-family } \\
\text { GTP-binding protein Obg }\end{array}$ & $\begin{array}{l}\text { Intermediary } \\
\text { metabolism and } \\
\text { respiration }\end{array}$ \\
\hline Rv2529 & Rv2529 & Unknown & Hypothetical protein & $\begin{array}{c}\text { Conserved } \\
\text { hypotheticals }\end{array}$ \\
\hline Rv2633c & Rv2633c & Unknown & Hypothetical protein & $\begin{array}{c}\text { Conserved } \\
\text { hypotheticals }\end{array}$ \\
\hline Rv2714 & Rv2714 & Unknown & $\begin{array}{l}\text { Conserved alanine and leucine } \\
\text { rich protein }\end{array}$ & $\begin{array}{c}\text { Conserved } \\
\text { hypotheticals }\end{array}$ \\
\hline Rv2884 & Rv2884 & Involved in transcriptional mechanism & $\begin{array}{l}\text { Probable transcriptional } \\
\text { regulatory protein }\end{array}$ & Regulatory proteins \\
\hline Rv2906c & $\operatorname{trmD}$ & $\begin{array}{c}\text { Specifically methylates guanosime-37 in } \\
\text { various TRNAS }\end{array}$ & $\begin{array}{c}\text { Daunorubicin-dim-transport } \\
\text { integral membrane protein ABC } \\
\text { transporter DrrB }\end{array}$ & $\begin{array}{l}\text { Cell wall and cell } \\
\text { processes }\end{array}$ \\
\hline Rv2937 & drrB & $\begin{array}{c}\text { Probably involved in active transport of } \\
\text { antibiotic and phthiocerol Dimycocerosate } \\
\text { (dim) across the membrane (export). May } \\
\text { act jointly to confer daunorubicin and } \\
\text { doxorubicin resistance by an export } \\
\text { mechanism }\end{array}$ & $\begin{array}{c}\text { Daunorubicin-dim-transport } \\
\text { integral membrane protein ABC } \\
\text { transporter DrrB }\end{array}$ & $\begin{array}{l}\text { Cell wall and cell } \\
\text { processes }\end{array}$ \\
\hline Rv2957 & Rv2957 & $\begin{array}{l}\text { Function unknown; probably involved in } \\
\text { cellular metabolism }\end{array}$ & Possible glycosyl transferase & $\begin{array}{l}\text { Intermediary } \\
\text { metabolism and } \\
\text { respiration }\end{array}$ \\
\hline Rv2958c & Rv2958c & $\begin{array}{l}\text { Unknown; probably involved in cellular } \\
\text { metabolism.Possibly involved in resistance } \\
\text { to killing by human macrophages }\end{array}$ & Possible glycosyl transferase & $\begin{array}{l}\text { Intermediary } \\
\text { metabolism and } \\
\text { respiration }\end{array}$ \\
\hline Rv3228 & Rv3228 & Unknown & Conserved hypothetical protein & $\begin{array}{c}\text { Conserved } \\
\text { hypotheticals }\end{array}$ \\
\hline Rv3282 & Rv3282 & Unknown & Conserved hypothetical protein & $\begin{array}{c}\text { Conserved } \\
\text { hypotheticals }\end{array}$ \\
\hline Rv3321c & vapB44 & Unknown & Possible antitoxin VapB44 & $\begin{array}{l}\text { Virulence, } \\
\text { detoxification, } \\
\text { adaptation }\end{array}$ \\
\hline Rv3330 & dacB1 & $\begin{array}{c}\text { Involved in peptidoglycan synthesis (at } \\
\text { final stages). Hydrolyzes the bound } \\
\text { D-alanyl-D-alanine }\end{array}$ & $\begin{array}{c}\text { Probablepenicillin-binding } \\
\text { protein DacB1 } \\
\text { (D-alanyl-D-alanine } \\
\text { carboxypeptidase) (DD } \\
\text { transpeptidase) }\end{array}$ & $\begin{array}{l}\text { Cell wall and cell } \\
\text { processes }\end{array}$ \\
\hline
\end{tabular}


Table 4. Cont.

\begin{tabular}{|c|c|c|c|c|}
\hline Locus Tag & $\begin{array}{l}\text { Gene } \\
\text { Symbol }\end{array}$ & Function & Product & $\begin{array}{l}\text { Functional } \\
\text { Category }\end{array}$ \\
\hline Rv3335c & Rv3335c & Unknown & $\begin{array}{l}\text { Probable conserved integral } \\
\text { membrane protein }\end{array}$ & $\begin{array}{l}\text { Cell wall and cell } \\
\text { processes }\end{array}$ \\
\hline Rv3338 & Rv3338 & Unknown & Conserved hypothetical protein & $\begin{array}{c}\text { Conserved } \\
\text { hypotheticals }\end{array}$ \\
\hline Rv3426 & PPE58 & unknown & PPE family protein PPE58 & $\mathrm{PE} / \mathrm{PPE}$ \\
\hline Rv3429 & PPE59 & unknown & PPE family protein PPE59 & $\mathrm{PE} / \mathrm{PPE}$ \\
\hline Rv3712 & Rv3712 & $\begin{array}{l}\text { Function unknown; probably involved in } \\
\text { cellular metabolism }\end{array}$ & Possible ligase & $\begin{array}{l}\text { Intermediary } \\
\text { metabolism and } \\
\text { respiration }\end{array}$ \\
\hline Rv3737 & Rv3737 & Unknown & $\begin{array}{l}\text { Probable conserved } \\
\text { transmembrane protein }\end{array}$ & $\begin{array}{l}\text { Cell wall and cell } \\
\text { processes }\end{array}$ \\
\hline Rv3760 & Rv3760 & Unknown & $\begin{array}{l}\text { Possible conserved membrane } \\
\text { protein }\end{array}$ & $\begin{array}{l}\text { Cell wall and cell } \\
\text { processes }\end{array}$ \\
\hline Rv3824c & papA1 & Involved in sulfolipid-1 (SL-1) biosynthesis & $\begin{array}{l}\text { Conserved polyketide synthase } \\
\text { associated protein PapA1 }\end{array}$ & Lipid metabolism \\
\hline
\end{tabular}

\subsection{Differentially Expressed Proteins in the DR Strains}

We further compared the differentially expressed proteins in the $3 \mathrm{DR}$ strains. Compared to the RR strain, 35 proteins were up-regulated, while 50 proteins were downregulated in the MDR strain (Figure 3A). Forty-one proteins were significantly increased, while 64 proteins were decreased in the XDR strain (Figure 3B). Importantly, both MDR and XDR strains showed high expression of 5 proteins: Rv2272, smtB, lpqB, icd1, and folK (Figure 3C, Table 5) and low expression of 12 proteins: esxK, PPE19, Rv1534, rpmI, ureA, tpx, mpt64, frr, Rv3678c, esxB, esxA, and espL (Figure 3D, Table 6). In addition, 22 and 44 proteins were specifically expressed in the MDR and XDR strains, respectively, when compared to the RR strain (Figure 3E). Importantly, 8 proteins were specifically expressed in the MDR and XDR strains: nrp, PPE3, mntH, Rv1188, Rv1473, nadB, PPE36, and sseA (Figure 3E, Table 7). In contrast, a total of 785 proteins were not detected in either MDR or XDR strains when compared to the DS strain (Figure 3F). Among them, 292 proteins were not identified in both MDR and XDR strains (Figure 3F), most of which were conserved hypotheticals (Figure S1).

In addition, 52 proteins were identified up-regulated, while 45 proteins were downregulated in the XDR strain when compared to the MDR strain (Figure 4A). The majority of the up-regulated proteins in the XDR strain were involved in information pathways (Figure 4B), while the down-regulated proteins were involved in intermediary metabolism and respiration (Figure 4C). Moreover, a total of 316 proteins were especially expressed in the XDR strain, while 92 proteins were especially expressed in the MDR strain (Figure S2). Most of the especially expressed proteins in either the XDR or MDR strain belonged to intermediary metabolism and respiration, conserved hypotheticals, and cell wall and cell processes. 
A

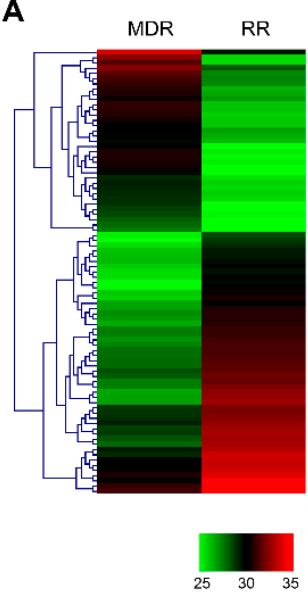

B

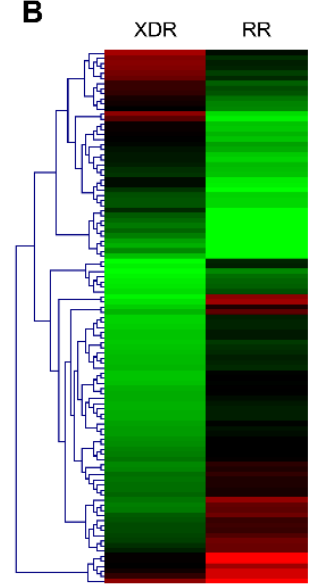

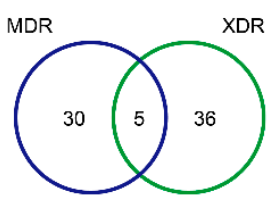

D

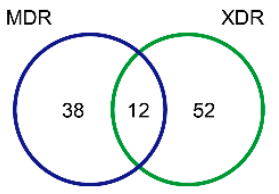

E

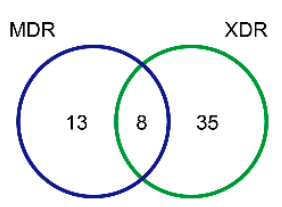

$\mathbf{F}$

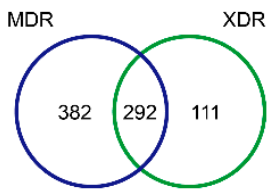

Figure 3. Differentially expressed proteins in the MDR, XDR, and RR strains. (A,B) Hierarchical clustering of proteins differentially expressed in the MDR vs. RR strains (A) and the XDR vs. RR strains (B). Log2 ratios were calculated based on LFQ intensity. (C-F) Venn diagram showed the number of up-regulated (C), down-regulated (D), especially expressed (E), and unexpressed (F) proteins in either MDR or XDR strains, when compared to the RR strain. RR, rifampin-resistant; MDR, multidrug-resistant; XDR, extensively drug-resistant; LFQ, label-free quantitation.

Table 5. Up-regulated genes in the MDR and XDR strains compared to the RR strain, sorted in order of gene number.

\begin{tabular}{|c|c|c|c|c|}
\hline $\begin{array}{l}\text { Locus } \\
\text { Tag }\end{array}$ & $\begin{array}{l}\text { Gene } \\
\text { Symbol }\end{array}$ & Function & Product & $\begin{array}{c}\text { Functional } \\
\text { Category }\end{array}$ \\
\hline Rv2272 & Rv2272 & Unknown & Probable conserved transmembrane protein & $\begin{array}{l}\text { Cell wall and cell } \\
\text { processes }\end{array}$ \\
\hline Rv2358 & $\mathrm{smtB}$ & $\begin{array}{l}\text { Involved in transcriptional } \\
\text { mechanism }\end{array}$ & $\begin{array}{l}\text { Probable transcriptional regulatory protein } \\
\text { SmtB (probably ArsR-family) }\end{array}$ & Regulatory proteins \\
\hline Rv3244c & lpqB & Unknown & Probable conserved lipoprotein LpqB & $\begin{array}{l}\text { Cell wall and cell } \\
\text { processes }\end{array}$ \\
\hline Rv3339c & Icd1 & $\begin{array}{l}\text { Involved in the KREBS cycle } \\
\text { [catalytic activity: isocitrate }+ \\
\begin{array}{c}\mathrm{NADP}(+)= \\
\text { - }- \text {-oxoglutarate }+\mathrm{CO}(2) \\
+\mathrm{NADPH}]\end{array}\end{array}$ & $\begin{array}{c}\text { Probable isocitrate dehydrogenase [NADP] } \\
\text { Icd1 (oxalosuccinate decarboxylase) (IDH) } \\
\text { (NADP }{ }^{+} \text {-specific ICDH) (IDP) }\end{array}$ & $\begin{array}{l}\text { Intermediary } \\
\text { metabolism and } \\
\text { respiration }\end{array}$ \\
\hline Rv3606c & folK & $\begin{array}{l}\text { Involved in dihydrofolate } \\
\text { biosynthesis (at the first step) } \\
\text { [catalytic activity: ATP + 2-amino- } \\
\text { 4-hydroxy-6-hydroxymethyl-7,8- } \\
\text { dihydropteridine = AMP + } \\
\text { 2-amino-7,8-dihydro-4-hydroxy-6- } \\
\text { (diphosphooxymethyl)pteridine] }\end{array}$ & $\begin{array}{c}\text { 2-amino-4-hydroxy-6- } \\
\text { hydroxymethyldihydropteridine } \\
\text { pyrophosphokinase FolK (7,8-dihydro-6- } \\
\text { hydroxymethylpterin-pyrophosphokinase) } \\
\text { (HPPK) (6-hydroxymethyl-7,8-dihydropterin } \\
\text { pyrophosphokinase) (PPPK) (2-amino-4- } \\
\text { hydroxy-6-hydroxymethyldihydropteridine } \\
\text { diphosphokinase) (7,8-dihydro-6- } \\
\text { hydroxymethylpterin-diphosphokinase) } \\
\text { (6-hydroxymethyl-7,8-dihydropterin } \\
\text { diphosphokinase) }\end{array}$ & $\begin{array}{l}\text { Intermediary } \\
\text { metabolism and } \\
\text { respiration }\end{array}$ \\
\hline
\end{tabular}


Table 6. Down-regulated genes in the MDR and XDR strains compared to the RR strain, sorted in order of gene number.

\begin{tabular}{|c|c|c|c|c|}
\hline Locus Tag & Gene Symbol & Function & Product & Functional Category \\
\hline Rv1197 & esxK & Function unknown & $\begin{array}{l}\text { ESAT-6 like protein } \\
\text { EsxK (ESAT-6 like } \\
\text { protein 3) }\end{array}$ & $\begin{array}{l}\text { Cell wall and cell } \\
\text { processes }\end{array}$ \\
\hline Rv1361c & PPE19 & Function unknown & $\begin{array}{l}\text { PPE family protein } \\
\text { PPE19 }\end{array}$ & PE/PPE \\
\hline Rv1534 & Rv1534 & $\begin{array}{l}\text { Possibly involved in a transcriptional } \\
\text { mechanism }\end{array}$ & $\begin{array}{l}\text { Probable } \\
\text { transcriptional } \\
\text { regulator }\end{array}$ & Regulatory proteins \\
\hline Rv1642 & rpmI & Translation & $\begin{array}{l}50 \text { S ribosomal protein } \\
\text { L35 RpmI }\end{array}$ & $\begin{array}{l}\text { Information } \\
\text { pathways }\end{array}$ \\
\hline Rv1848 & ureA & $\begin{array}{l}\text { Involved in the conversion of urea to } \mathrm{NH}_{3} \\
\text { [catalytic activity: urea }+\mathrm{H}_{2} \mathrm{O}=\mathrm{CO}_{2}+2 \mathrm{NH}_{3} \text { ] }\end{array}$ & $\begin{array}{c}\text { Urease gamma subunit } \\
\text { UreA (urea } \\
\text { amidohydrolase) }\end{array}$ & $\begin{array}{l}\text { Intermediary } \\
\text { metabolism and } \\
\text { respiration }\end{array}$ \\
\hline Rv1932 & $\operatorname{tpx}$ & $\begin{array}{l}\text { Has antioxidant activity. Could remove } \\
\text { peroxides or } \mathrm{H}(2) \mathrm{O}(2)\end{array}$ & $\begin{array}{l}\text { Probable thiol } \\
\text { peroxidase Tpx }\end{array}$ & $\begin{array}{c}\text { Virulence, } \\
\text { detoxification, and } \\
\text { adaptation }\end{array}$ \\
\hline Rv1980c & mpt64 & Unknown & $\begin{array}{c}\text { Immunogenic protein } \\
\text { Mpt64 (antigen } \\
\text { Mpt64/MPB64) }\end{array}$ & $\begin{array}{l}\text { Cell wall and cell } \\
\text { processes }\end{array}$ \\
\hline Rv2882c & frr & $\begin{array}{l}\text { Responsible for the release of ribosomes from } \\
\text { messenger RNA at the termination of protein } \\
\text { biosynthesis. May increase the efficiency of } \\
\text { translation by recycling ribosomes from one } \\
\text { round of translation to another. }\end{array}$ & $\begin{array}{l}\text { Ribosome recycling } \\
\text { factor Frr (ribosome } \\
\text { releasing factor) (RRF) }\end{array}$ & $\begin{array}{l}\text { Information } \\
\text { pathways }\end{array}$ \\
\hline Rv3678c & Rv3678c & Function unknown & Conserved protein & $\begin{array}{l}\text { Conserved } \\
\text { hypotheticals }\end{array}$ \\
\hline Rv3874 & esxB & $\begin{array}{l}\text { Unknown. Exported protein cotranscribed } \\
\text { with Rv3875 I MT3989 | MTV027.10. }\end{array}$ & $\begin{array}{c}10 \text { kDa culture filtrate } \\
\text { antigen EsxB (LHP) } \\
\text { (CFP10) }\end{array}$ & $\begin{array}{l}\text { Cell wall and cell } \\
\text { processes }\end{array}$ \\
\hline Rv3875 & esxA & $\begin{array}{l}\text { Unknown. Elicits high level of inf-gamma } \\
\text { from memory effector cells during the first } \\
\text { phase of a protective immune response. } \\
\text { Exported protein cotranscribed with } \\
\text { Rv3874 I MT3988 I MTV027.09 | LHP I CFP10. }\end{array}$ & $\begin{array}{c}6 \text { kDa early secretory } \\
\text { antigenic target EsxA } \\
\text { (ESAT-6) }\end{array}$ & $\begin{array}{l}\text { Cell wall and cell } \\
\text { processes }\end{array}$ \\
\hline Rv3880c & espL & Function unknown & $\begin{array}{c}\text { ESX-1 } \\
\text { secretion-associated } \\
\text { protein EspL }\end{array}$ & $\begin{array}{l}\text { Cell wall and cell } \\
\text { processes }\end{array}$ \\
\hline
\end{tabular}


Table 7. Specifically expressed genes in the MDR and XDR strains compared to the RR strain, sorted in order of gene number.

\begin{tabular}{|c|c|c|c|c|}
\hline Locus Tag & Gene Symbol & Function & Product & Functional Category \\
\hline Rv0101 & nrp & Involved in lipid metabolism. & $\begin{array}{c}\text { Probable peptide } \\
\text { synthetase Nrp (peptide } \\
\text { synthase) }\end{array}$ & Lipid metabolism \\
\hline Rv0280 & PPE3 & Function unknown & PPE family protein PPE3 & $\mathrm{Pe} / \mathrm{ppe}$ \\
\hline Rv0924c & $\mathrm{mntH}$ & $\begin{array}{l}\mathrm{H}(+) \text {-stimulated, highly selective, divalent } \\
\text { cation uptake system. Responsible for the } \\
\text { translocation of the divalent metal across the } \\
\text { membrane. }\end{array}$ & $\begin{array}{l}\text { Divalent cation-transport } \\
\text { integral membrane } \\
\text { protein MntH (BRAMP) } \\
\text { (MRAMP) }\end{array}$ & $\begin{array}{c}\text { Cell wall and cell } \\
\text { processes }\end{array}$ \\
\hline Rv1188 & Rv1188 & $\begin{array}{l}\text { Oxidizes proline to glutamate for use as a } \\
\text { carbon and nitrogen source [catalytic activity: } \\
\text { L-proline }+ \text { acceptor }+\mathrm{H}_{2} \mathrm{O}= \\
\text { (S)-1-pyrroline-5-carboxylate }+ \text { reduced } \\
\text { acceptor] }\end{array}$ & $\begin{array}{l}\text { Probable proline } \\
\text { dehydrogenase }\end{array}$ & $\begin{array}{l}\text { Intermediary } \\
\text { metabolism and } \\
\text { respiration }\end{array}$ \\
\hline Rv1473 & Rv1473 & $\begin{array}{l}\text { Thought to be involved in active transport of } \\
\text { macrolide across the membrane (export). } \\
\text { Macrolide antibiotics resistance by an export } \\
\text { mechanism. Responsible for energy coupling } \\
\text { to the transport system. }\end{array}$ & $\begin{array}{l}\text { Probable } \\
\text { macrolide-transport } \\
\text { ATP-binding protein } \\
\text { ABC transporter }\end{array}$ & $\begin{array}{c}\text { Cell wall and cell } \\
\text { processes }\end{array}$ \\
\hline Rv1595 & nadB & $\begin{array}{l}\text { Quinolinate biosynthesis. Catalyzes the } \\
\text { oxidation of L-aspartate to iminoaspartate } \\
\text { which is condensed with dihydroxyacetone } \\
\text { phosphate to quinolinate under the action of } \\
\text { quinolinate synthase a [catalytic activity: } \\
\text { L-aspartate }+\mathrm{H}(2) \mathrm{O}+\mathrm{O}(2)=\text { oxaloacetate }+ \\
\mathrm{NH}(3)+\mathrm{H}(2) \mathrm{O}(2)]\end{array}$ & $\begin{array}{c}\text { Probable L-aspartate } \\
\text { oxidase NadB }\end{array}$ & $\begin{array}{l}\text { Intermediary } \\
\text { metabolism and } \\
\text { respiration }\end{array}$ \\
\hline Rv2108 & PPE36 & Function unknown & $\begin{array}{l}\text { PPE family protein } \\
\text { PPE36 }\end{array}$ & $\mathrm{PE} / \mathrm{PPE}$ \\
\hline Rv3283 & sseA & $\begin{array}{l}\text { Possibly a sulfotransferase involved in the } \\
\text { formation of thiosulfate [catalytic activity: } \\
\text { thiosulfate + cyanide = sulfite + thiocyanate]. }\end{array}$ & $\begin{array}{l}\text { Probable thiosulfate } \\
\text { sulfurtransferase SseA } \\
\text { (rhodanese) (thiosulfate } \\
\text { cyanide transsulfurase) } \\
\quad \text { (thiosulfate } \\
\text { thiotransferase) }\end{array}$ & $\begin{array}{l}\text { Intermediary } \\
\text { metabolism and } \\
\text { respiration }\end{array}$ \\
\hline
\end{tabular}


A

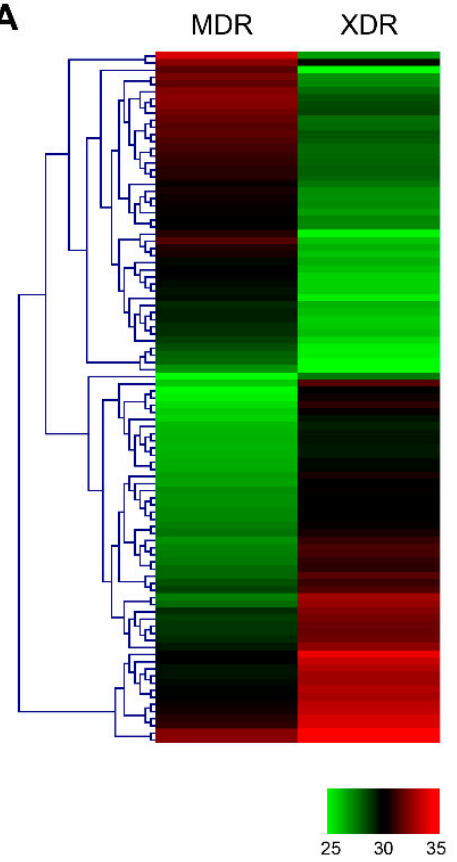

B

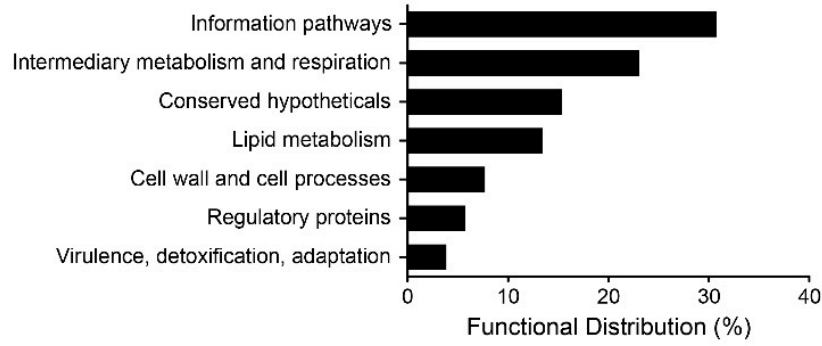

C

Intermediary metabolism and respiration Conserved hypotheticals

Cell wall and cell processes

Virulence, detoxification, adaptation

Lipid metabolism

Regulatory proteins

Information pathways

PE/PPE

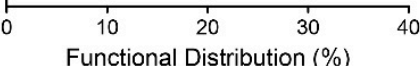

Figure 4. Up and down-regulated proteins between MDR and XDR strains. (A) Hierarchical clustering of proteins differentially expressed in the XDR vs. MDR strains. Log2 ratios were calculated based on LFQ intensity. (B,C) Functional distribution of the up-regulated (B) or down-regulated $(\mathbf{C})$ proteins in the XDR strain, when compared to the MDR strain, according to the TubercuList Functional Category (http:/ / svitsrv8.epfl.ch/tuberculist/ accessed on 18 February 2021). RR, rifampin-resistant; MDR, multidrug-resistant; XDR, extensively drug-resistant; LFQ, label-free quantitation.

\subsection{The Molecular Mechanisms of the Differentially Expressed Proteins in the DR vs. DS Strains}

To better understand the association of the 20 up-regulated proteins in DR strains, we mapped them onto STRING database to build a PPI network (Figure S3A). Only Rv1780 could not play a part in the construction of the network. Function enrichment analysis against gene ontology (GO) in this network showed that for biological processes, this network was enriched in organonitrogen compound metabolic process, water-soluble vitamin biosynthetic process, riboflavin biosynthetic and metabolic process, drug metabolic process, and folic-acid-containing compound biosynthetic and metabolic process. For molecular function, it was significantly enriched in proteasome binding, purine ribonucleotide binding, and drug binding. For cellular components, it was significantly enriched in the proteasome complex, cytoplasm, and cell wall (Tables S2-S4).

Thirty down-regulated proteins of DR strains were mapped onto STRING database to build a PPI network (Figure S3B). PPE36, rpmB1, and Rv3295 could not play roles in the construction of the network. Function enrichment analysis against GO in this network showed that for biological processes, this network was enriched in pathogenesis, cellular oxidant detoxification, protein transmembrane transport, evasion or tolerance of host immune response, response to an external stimulus, and cellular response to a chemical stimulus. For molecular function, it was significantly enriched in antioxidant activity, peroxidase activity, and peroxiredoxin activity. For cellular components, it was significantly enriched in the extracellular region, cell wall, and plasma membrane (Tables S5-S7).

Other 12 specific expressed proteins of DR strains were mapped onto STRING database to build a PPI network (Figure S3C). Only Rv1360 could not take part in the construction of the network. Function enrichment analysis against GO in this network showed that for biological processes, this network was enriched in coenzyme biosynthetic process, NAD biosynthetic and metabolic process, and Mo-molybdopterin cofactor metabolic and biosynthetic process. For cellular components, it was significantly enriched in the molybdopterin synthase complex (Tables S8 and S9). 
In addition, 41 undetected proteins in the DR strains were mapped onto STRING database to build a PPI network (Figure S3D). Only Rv1424c could not participate in the construction of the network. Function enrichment analysis against GO in this network showed that for biological processes, this network was enriched in peptidoglycan-based cell wall biogenesis and antibiotic transport. For cellular components, it was significantly enriched in polyketide synthase complex and catalytic complex (Tables S10 and S11).

\section{Discussion}

Due to the emergence of MDR and XDR strains, current vaccination strategies and antiTB drugs have been proved insufficient to contain this considerable trouble [5]. Anti-TB drug resistance has been reported to be associated with specific mutations in the regulatory and/or structural regions of target genes, as mentioned above [5,21]. In the present study, we identified 2515 proteins through LFQ among DS, RR, MDR, and XDR strains. We found iniC, Rv2141c, folB, and Rv2561 were up-regulated in both RR and MDR strains, while fadE9, espB, espL, esxK, and Rv3175 were down-regulated in the three DR strains when compared to the DS strain. In addition, lprF, mce2R, mce2B, and Rv2627c were specifically expressed in the three DR strains, and 41 proteins were not detected compared to the DS strain. Functional category showed that these differentially expressed proteins were mainly involved in the cell wall and cell processes. Compared to the RR strain, Rv2272, smtB, lpqB, icd1, and folK were up-regulated, while esxK, PPE19, Rv1534, rpmI, ureA, tpx, mpt64, frr, Rv3678c, esxB, esxA, and espL were down-regulated in both MDR and XDR strains. Additionally, nrp, PPE3, mntH, Rv1188, Rv1473, nadB, PPE36, and sseA were specifically expressed in both MDR and XDR strains, whereas 292 proteins were undetected when compared to the RR strain. When compared between MDR and XDR strains, 52 proteins were identified up-regulated, while 45 proteins were down-regulated in the XDR strain. Three hundred and sixteen proteins were specially expressed in the XDR strain, while 92 proteins were specially expressed in the MDR strain. Bioinformatics studies like protein-protein interactions showed their participation in virulence and drug resistance [22]. Therefore, these differentially expressed proteins are of great significance for exploring effective control strategies of DR-TB.

Proteomics play significant roles in the medical research era, for example, for understanding the relation between proteins, discovery of drugs, and diagnosis of diseases. In our report, we found that iniC, Rv2141c, folB, and Rv2561 were up-regulated in both RR and MDR strains compared to the DS strains. IniC (Rv0343) is INH inducible protein, with the highest tendency triggering resistance for both INH and EMB [23]. The gene iniC was structured in an operon, controlled by iniBAC promoter, and up-regulated via several cell envelope inhibitors such as INH and other cell wall-active drugs [24]. Rv2141c is a conserved protein, which is also expressed in Mycobacterium smegmatis [25] and significantly inhibits cell death [26]. FolB (Rv3607c) is an metabolic persister gene involved in folate/dihydroneopterin biosynthetic pathway. FolB protein is essential to the survival of $M$. tuberculosis and might be used as novel targets for the development of drugs [27]. Rv2561 is a "conserved hypothetical" protein with unknown functions, up-regulated in broth-grown M. tuberculosis H37Ra and H37Rv strains [28]. Rv2561 was related to druggable proteins [29]. We demonstrated the corresponding PPI network of the up-regulated proteins of DR strains was enriched in many metabolic pathways. Metabolic pathways play a significant role in drug resistance as part of the global response and a novel strategy against DR bacteria [30]. Potential drug targets from these related pathways include amino acid metabolism, energy metabolism, lipid metabolism, and vitamin cofactor biosynthetic pathways. These pathways could be beneficial for the discovery of broad-spectrum drugs [31]. Several folate pathway determinates have been attributed to the sulfonamide resistance in M. tuberculosis, and the frontline anti-TB drugs such as ETH, INH, and PAS have been revealed as potential inhibitors of the folate biosynthetic pathway [32].

We carried out a proteomics study of $M$. tuberculosis differentially expressed proteins and determined that espB, espL, esxK, and Rv3175 were down-regulated in the three DR 
strains when compared to the DS strain. EspB (Rv3881c) protein is a substrate for the ESX-1 type VII protein secretion system, which is required for the virulence and growth in macrophages, [33]. EspL (Rv3880c) interacts with EspD and has been discovered to maintain the stability of the effector proteins and ESX-1 substrates that are involved in ESAT-6 secretion and stabilization of EspE expression. EspL has a strong DNA-binding ability and plays a role as a chaperone [34]. EsxK (Rv1197) is a putative interacting protein that belongs to primary secretory (ESX-6) system antigenic targets [35]. Rv3175 is a possible amidase involved in cellular metabolism [36]. However, this basal level of amidase activities is sufficient for the utilization of nicotinamide by Mycobacterium bovis, whereas it is not enough to regulate PZA susceptibility [37]. We found the corresponding PPI network of the down-regulated proteins of DR strains was enriched in antioxidant activity, peroxidase activity, and peroxiredoxin activity. The reduced activity of oxidative stress in M. tuberculosis is crucial for resistance to clofazimine, a peroxide-generating drug [38]. The decrease or loss of peroxidase activity is the most common genetic change related to INH resistance [38].

In addition, lprF, mce2R, mce2B, and Rv2627c were specifically expressed in the three DR strains when compared to the DS strains. LprF (Rv1368) modifications in various strains resulted from resisting antimicrobial agents and conserved lipoprotein synthesis pathway. Lipoproteins are virulence factors of $M$. tuberculosis; $M$. bovis is considered as a model organism to study the mutation of lipoprotein in Mycobacteria [39]. LprF possess transmembrane helices and were found to be potential candidates for serodiagnostic techniques $[39,40]$. Similarly, lprF crystal structure has been determined, which is a functional homolog to lprG that offers lprF transferring diacylated glycolipid from the plasma membrane to the cell wall [41]. Mce2R (Rv0586) is a Guntur/FadR family protein in M. tuberculosis identified as FadR homolog that acts as a fatty acid reactive transcriptional regulator of $M$. tuberculosis mycolic acid biosynthesis [42]. Protein DNA interaction (PDI) data demonstrate that novel target genes (mce2R) play essential roles in the regulation of multidrug resistance, cell wall synthesis, and intracellular growth of M. tuberculosis [43]. Mce2B (Rv0590) is mce family protein thought to be involved in host cell invasion [44]. However, mce operons have been associated with the attenuation of $M$. tuberculosis virulence [45]. Rv2627c belongs to DosR regulon encoded proteins and latency-associated antigens in case of latently infected individuals, which induced high levels and long-term of IFN- $\gamma$ responses [46,47]. Other 41 proteins were not detected in the three DR strains when compared to the DS strains, and several such as Rv3321c (VapB44), possible antitoxin protein [48], Rv3426 (PPE58), PPE family protein, and conserved membrane proteins Rv2219A [49] and Rv3760 remain unknown function. They might be used as a potential drug target for future research.

Moreover, we further analyzed the differentially expressed proteins among the 3 DR strains and found Rv2272, smtB, lpqB, icd1, and folK were highly expressed in both MDR and XDR strains when compared to the RR strain. Rv2272 is a transmembrane protein involved in Sigma factor E regulation during macrophage infection, which is helpful for the pathogen to deal with environmental stress and to inhibit the host antibacterial responses [50]. SmtB (Rv2358) is a Zinc-binding transcriptional regulator that belongs to the ArsR family protein, which affects the elasticity of the N-terminal trans-activation domain and shows amino acid variations specific to the Beijing lineage of $M t b$ [51]. LpqB (Rv3244c) is a putative lipoprotein, which plays an important role in cell growth and cell wall metabolism [52]. The encoding gene of lpqB is located immediately downstream of MtrA and MtrB, so that lpqB might act as a modulator of MtrB activity [53]. Icd-1 (Rv3339c) has been identified in the $M$. tuberculosis genome as a probable isocitrate dehydrogenase gene encoded for functional energy cycle enzymes [54]. Folk (Rv3606c) protein is involved in the dihydrofolate biosynthesis pathway, validated as a drug target $[55,56]$.

On the other hand, 12 proteins, namely, esxK, PPE19, Rv1534, rpmI, ureA, tpx, mpt64, frr, Rv3678c, esxB, esxA, and espL, were down-regulated in both MDR and XDR strains when compared to the RR strain. Except for esxK and espL discussed above, PPE19 (Rv1361c) has been identified as a putative target of MtrA [57], and a genomics indicator 
of susceptibility to amoxicillin-clavulanate [58]. Rv1534 protein is possibly involved in a transcriptional process, metabolism, and cell development [59]. RpmI (Rv1642) is an active virulence operon involved in protein synthesis and is associated with invasion and intercellular resistance [60]. UreA (Rv1848) is involved in the conversion of urea to ammonia (NH3). Urease, encoded within an operon consists of ureA subunit, is important for the survival of $M$. tuberculosis in the lung tissue and remains an attractive target for chemotherapeutic TB [61]. TpX (Rv1932) thiol peroxidase has been characterized as a cysteine peroxiredoxin which serves as a reaction site for either oxidizing or reducing substrates [62]. It is the most efficient enzyme to protect $M$. tuberculosis against oxidative and nitrosative stress and is overexpressed in the presence of ofloxacin (OFX) and moxifloxacin (MOX) [63,64]. Mpt64 (Rv1980c) binds to streptomycin, whose overexpression might cumulatively neutralize or compensate for the drug's effect and contribute to streptomycin resistance [65]. Frr (Rv2882c) encodes the ribosome recycling factor and maintains translation fidelity by preventing aberrant reinitiation of translation downstream of the mRNA stop codon [66]. Frr protein might be involved in the ofloxacin modulation or neutralization and causes ofloxacin resistance [67]. Rv3678c conserved protein has an unknown function, studied as a regulator against stress-responsive gene [68]. EsxB (Rv3874) and EsxA (Rv3875) are two major substrates of the ESX-1 system. EsxA helps breach the phagosomal membrane and facilitate the escape of $M$. tuberculosis into the cytosol [69,70].

More importantly, both MDR and XDR strains specifically expressed 8 proteins: nrp, PPE3, mntH, Rv1188, Rv1473, nadB, PPE36, and sseA, when compared to the RR strain. Nrp (Rv0101) is a peptide synthetase that plays a role in in vivo infection during survival [58]. PPE3 (Rv0280) and PPE36 (Rv2108) are members of the PPE family with an unknown function. PPE3 was studied as a putative genomic marker of amoxicillin/clavulanate susceptibility [58], while PPE36 was involved in the heme utilization by M. tuberculosis [71]. $\mathrm{MntH}(\mathrm{Rv} 0924 \mathrm{c})$ is an integral membrane protein of M. tuberculosis that mediates divalent cation transportation [72]. Rv1188 gene encodes for proline dehydrogenase. Proline metabolism is an important player in the persistence of $M$. tuberculosis through detoxification of methyl-glyoxal [73]. Rv1473 is a predicted drug efflux pump involved in mycobacteria intrinsic drug resistance through the efflux process [74]. NadB (Rv1595) is an L-aspartate oxidase involved in the differentially regulated conversion of aspartate to $\mathrm{NAD}^{+}$in response to nitrogen stress [49]. SseA (Rv3283) is a thiosulfate sulfurtransferase down-regulated in the Beijing B0/W148 strains, leading to enhanced oxidative DNA damage, mutations, and drug resistance [75].

Therefore, our comparative proteomics study obtained differentially expressed candidate proteins of DR strains, and the functional category of these proteins laid the infrastructure for the establishment of effective control strategies for DR-TB.

\section{Materials and Methods}

\subsection{Mycobacterial Growth}

Three kinds of clinical Mtb DR strains, namely, RR, MDR, and XDR strains, were obtained from the DR-TB patients in Wuhan Pulmonary Hospital (Wuhan, China). The standard H37Rv strain was regarded as the DS strain. All strains were grown in Middlebrook 7H9 liquid medium (Difco Laboratories, Sparks, MD, USA) with Tween 80 0.05\% and ADC $10 \%$ enrichment containing bovine serum albumin (BSA)-dextrose-catalase $0.5 \%$ (Difco) at $37^{\circ} \mathrm{C}$ for $10-14$ days to their mid-log phase. For proteomic analysis, strains were washed, passaged one time in Sauton's medium, and then grown for 2 days to early $\log$ phase.

\subsection{DST of Clinical DR Strains}

All experiments using live clinical $M t b$ strains were conducted in the biosafety level 2 plus laboratory of Wuhan Pulmonary Hospital. All strains were tested for drug susceptibility against 6 anti-TB drugs according to the World Health Organization (WHO) and Clinical and Laboratory Quality Institute (CLSI) guidelines. Löwenstein-Jensen commercial 
media (Wuhan, China) containing antibiotics were used in the proportion methods to test all antibiotics. The critical concentrations for INH (Sigma, Oakville, ON, Canada) were $0.2 \mathrm{mg} / \mathrm{L}$, RIF (Sigma) $40.0 \mathrm{mg} / \mathrm{L}$, ethambutol (EMB, Sigma) $2.0 \mathrm{mg} / \mathrm{L}$, levofloxacin (LFX, Sigma) $2.0 \mathrm{mg} / \mathrm{L}$, moxifloxacin (MOX, Sigma) $2.0 \mathrm{mg} / \mathrm{L}$, and kanamycin (KAN, Sigma) $30.0 \mathrm{mg} / \mathrm{L}$, respectively. After 3 weeks of incubation at $37^{\circ} \mathrm{C}$, their DST results were confirmed (Table S1).

\subsection{Whole Cell Lysate Protein Extraction of Mycobacteria}

The mycobacterial lysate was obtained under ultrasonic decomposition at an interval of $10 \mathrm{~s}$ (100 W, 10 circles). Then, samples were placed in a bath full of boiling water for $10 \mathrm{~min}$ and clarified by centrifugation $(13,400 \mathrm{rpm}$ for $30 \mathrm{~min})$. The supernatant containing the whole cell lysate proteins was retained and determined the concentrations with BCA according to the manufacturer's instructions. The lysate was sterilized through a filter membrane with the pore diameter of $0.22 \mu \mathrm{m}$ (Pall Corporation, Ann Arbour, MI, USA) and stored at $-80{ }^{\circ} \mathrm{C}$ until further analysis [76]. The lysate proteins were identified by $12 \%$ SDS-PAGE.

\subsection{Filter-Aided Sample Preparation (FASP) Digestion}

FASP digestion was performed following the published protocol [77]. Briefly, $30 \mu \mathrm{g}$ of each protein extract from different mycobacterial strains was added with dithiothreitol $(100 \mathrm{mM})$ and incubated at $95^{\circ} \mathrm{C}$ for $5 \mathrm{~min}$. There were three replicate experiments for each strain. Samples were mixed up with $200 \mu \mathrm{L}$ of UA (8 M Urea, $150 \mathrm{mM}$ Tris-HCl, pH 8.0) and centrifuged at $14,000 \times g$ for $15 \mathrm{~min}$ at $25^{\circ} \mathrm{C}$. The clean-up step was repeated. Then, samples were added with $100 \mu \mathrm{L}$ iodoacetamide (IAA) solution (50 mM IAA in UA) and mixed at $600 \mathrm{rpm}$ in a thermo-mixer for $1 \mathrm{~min}$, incubated without mixing for $30 \mathrm{~min}$ in the dark, and centrifuged at $14,000 \times g$ for $10 \mathrm{~min}$. Then, samples were mixed up with $100 \mu \mathrm{L}$ UA buffer twice, centrifuged at $14,000 \times g$ for $10 \mathrm{~min}$, and mixed up with $100 \mu \mathrm{L}$ $\mathrm{NH}_{4} \mathrm{HCO}_{3}$ buffer twice. Then, samples were added with $40 \mu \mathrm{L}$ Trypsin buffer $(2 \mu \mathrm{g}$ Trypsin in $40 \mu \mathrm{L} \mathrm{NH}_{4} \mathrm{HCO}_{3}$ buffer) mixed at $600 \mathrm{rpm}$ in a thermo-mixer for $1 \mathrm{~min}$, and incubated for $16-18 \mathrm{~h}$ at $37^{\circ} \mathrm{C}$. The filtrate was desalted using C18-SD Extraction Disk Cartridge and estimated by measuring absorbance at $280 \mathrm{~nm}$.

\subsection{LC-MS/MS Analysis}

An EASY-nLC 1000 ultra-high pressure system (Thermo Scientific/Proxeon, Odense, Denmark) was used for LC-MS/MS analysis. Briefly, about $2 \mu \mathrm{g}$ of enzymatic hydrolysates was applied to a chromatographic column, packed with $3 \mu \mathrm{m}$ Reprosil pur $120 \mathrm{C} 18$ material, and balanced with mobile phase A ( $2 \%$ acetonitrile, $0.1 \%$ formic acid). Samples were separated using a $100 \mathrm{~min}$ gradient from 0 to $45 \%, 8 \mathrm{~min}$ from 45 to $100 \%$, and $10 \mathrm{~min}$ maintained at $100 \%$ of mobile phase B ( $84 \%$ acetonitrile, $0.1 \%$ formic acid) at $400 \mathrm{Nl} / \mathrm{min}$. Enzymatic hydrolysates were analyzed using automated data-dependent acquisition on a Q Exactive ${ }^{\mathrm{TM}} \mathrm{HF}$ hybrid Quadrupole Orbitrap ${ }^{\mathrm{TM}}$ mass spectrometer (Thermo Finnigan, Germany). Each MS scan (300-1800 m/z range) was acquired at a resolution of 70,000 and was followed by Top20 MS/MS scans triggered above an intensity of 17,500 using higher-energy C-trap dissociation (HCD).

\subsection{LFQ Analysis}

Raw label-free MS/MS data were processed using Maxquant (version 1.3.0.5) with default parameters. Parameters for protein searching were defined in Uniprot_mycobacterium_ tuberculosis_25618_H37RV_6541_20161114.fasta database (updated on 14 November 2016). For statistical evaluation of the data obtained, the posterior error probability and false discovery rate (FDR) were used. The FDR of 0.01 for proteins and peptides was required. The peptide identification was based on a search with an initial mass deviation of precursor ion of up to $20 \mathrm{ppm}$, with further data recalibrations and a new search with a 6-ppm deviation. MS/MS mass deviation was set to $20 \mathrm{ppm}$ for Q Exactive data and 0.5 Da for 
any LTQ-Orbitrap data. To match identifications across different replicated and adjacent fractions, the "match between runs" options in MaxQuant was enabled within a time window of 2 min. Proteins and peptides identified and quantified by at least two out of three replicates were used to compare different sample preparation protocols [78]. Significance $B$ test with a FDR value $<5 \%$ was applied to identify proteins for which the abundance was significantly changed between the two $M t b$ strains [79]. Workflow of the label-free quantitative (LFQ) proteomics was shown in Figure 5.

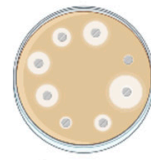

(1) DST

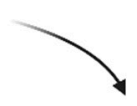

$\mathrm{RR}$

WT

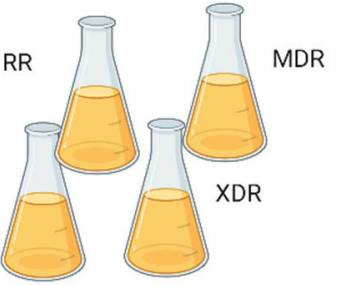

(2) Mycobacterium tuberculosis strain whole cell lysate

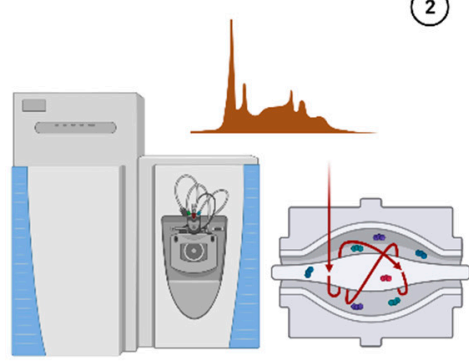

(4) Orbitrap Based Mass Spectrometry Analysis

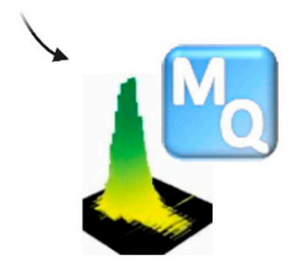

(5) MaxQuant Perseus)
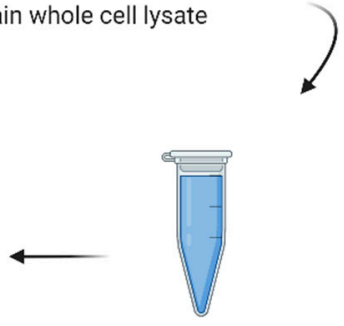

(3) FASP Digestion

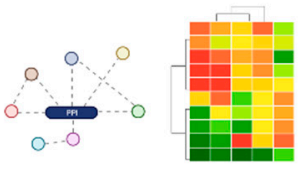

(6) Bioinformatics Analysis

Figure 5. Workflow of the label-free quantitative (LFQ) proteomics.

\subsection{Bioinformatics Analysis}

Proteomics data were performed by using hierarchical cluster analysis Multi Experiment Viewer (MeV 4.0) software. Tuberculist database was used for functional categories of the differently expressed genes (http: / / svitsrv8.epfl.ch/tuberculist/ accessed on 18 February 2021). The differently expressed proteins identified from the proteomics results were mapped onto the STRING database (http: / / string-db.org /) to develop protein-protein interaction (PPI) networks (Confidence score $>0.4$, accessed on 18 February 2021). Functional enrichments of each network were analyzed and displayed on the webpage.

Supplementary Materials: The following are available online at https:/ / www.mdpi.com/article/ 10.3390/pathogens10050607/s1, Figure S1: Functional distribution of the unexpressed proteins in both MDR and XDR strains, when compared to the RR strain, according to the TubercuList Functional Category (http: / / svitsrv8.epfl.ch/tuberculist/, accessed on 18 February 2021), Figure S2: Functional distribution of the specially expressed proteins in either the XDR (A) or MDR (B) strains, according to the TubercuList Functional Category (http:/ / svitsrv8.epfl.ch/tuberculist/, accessed on 18 February 2021), Figure S3: The interaction network of the differentially expressed proteins in the DR vs. DS strains and other predicted functional partners, Table S1: The DST patterns of the RR-TB, MDR-TB and XDR-TB clinical isolates, Table S2: Biological Process enrichment in the PPI network of the up-regulated proteins of DR strains and other predicted functional partners, 
Table S3: Molecular Function enrichment in the PPI network of the up-regulated proteins of DR strains and other predicted functional partners, Table S4: Cellular Component enrichment in the PPI network of the up-regulated proteins of DR strains and other predicted functional partners, Table S5: Biological Process enrichment in the PPI network of the down-regulated proteins of DR strains and other predicted functional partners, Table S6: Molecular Function enrichment in the PPI network of the down-regulated proteins of DR strains and other predicted functional partners, Table S7: Cellular Component enrichment in the PPI network of the down-regulated proteins of DR strains and other predicted functional partners, Table S8: Biological Process enrichment in the PPI network of the specific expressed proteins of DR strains and other predicted functional partners, Table S9: Cellular Component enrichment in the PPI network of the specific expressed proteins of DR strains and other predicted functional partners, Table S10: Biological Process enrichment in the PPI network of the unexpressed proteins of DR strains and other predicted functional partners, Table S11: Cellular Component enrichment in the PPI network of the unexpressed proteins of DR strains and other predicted functional partners.

Author Contributions: X.F. and Y.H. designed this project. N.U., L.H., J.-L.B.N., S.C., Y.W., L.L., and E.B.M. analyzed the proteomics data. N.U., L.H., and J.-L.B.N. wrote the manuscript with support from X.F. The final manuscript was revised thoroughly by X.F. All authors have read and agreed to the published version of the manuscript.

Funding: This research was funded by National Mega-Projects of Science Research for the 13th Five-year Plan of China grant No. 2018ZX10302302002-001; the Open Research Fund Program of CAS Key Laboratory of Special Pathogens and Biosafety No.2016SPCAS00, Chinese Academy of Sciences, and the Natural Science Foundation of China grant No. 81971909.

Informed Consent Statement: Not applicable.

Data Availability Statement: The data used to support the findings of this study are available from the corresponding author upon request.

Acknowledgments: This work was supported by grants from the National Mega-Projects of Science Research for the 13th Five-year Plan of China (No. 2018ZX10302302002-001), the Open Research Fund Program of CAS Key Laboratory of Special Pathogens and Biosafety (No.2016SPCAS00), Chinese Academy of Sciences, and the Natural Science Foundation of China (No. 81971909).

Conflicts of Interest: The authors declare no conflict of interest.

\begin{abstract}
Abbreviations
TB, tuberculosis; BCG, Bacillus Calmette-Guerin; MDR-TB, multidrug-resistant TB; XDR-TB, extensively drug-resistant TB; INH, isoniazid; RIF, rifampicin; RR, rifampicin-resistant; DS, drug-sensitive; LFQ, label-free quantification; FASP, filter-aided sample preparation; DST, drug susceptibility testing.
\end{abstract}

\title{
References
}

1. World Health Organization. Global Tuberculosis Report 2019; World Health Organization: Geneva, Switzerland, 2019.

2. Yari, S.; Tasbiti, A.H.; Ghanei, M.; Shokrgozar, M.A.; Vaziri, B.; Mahdian, R.; Yari, F.; Bahrmand, A. Proteomic analysis of sensitive and multi drug resistant Mycobacterium tuberculosis strains. Microbiology 2016, 85, 350-358. [CrossRef]

3. Chen, B.; Zhang, D.; Wang, X.; Ma, W.; Deng, S.; Zhang, P.; Zhu, H.; Xu, N.; Liang, S. Proteomics progresses in microbial physiology and clinical antimicrobial therapy. Eur. J. Clin. Microbiol. Infect. Dis. 2017, 36, 403-413. [CrossRef]

4. Patel, V.J.; Thalassinos, K.; Slade, S.E.; Connolly, J.B.; Crombie, A.; Murrell, J.C.; Scrivens, J.H. A comparison of labeling and label-free mass spectrometry-based proteomics approaches. J. Proteome Res. 2009, 8, 3752-3759. [CrossRef]

5. Tasbiti, A.H.; Yari, S.; Ghanei, M.; Shokrgozar, M.; Fateh, A.; Siadat, S.; Vaziri, F.; Bahrmand, A. Proteins purified from Mycobacterium tuberculosis MDR and Susceptible clinical isolates: Identification by proteomics approach. Int. J. Mycobacteriol. 2015, 4, 96-97. [CrossRef]

6. Jenkins, H.E.; Zignol, M.; Cohen, T. Quantifying the burden and trends of isoniazid resistant tuberculosis, 1994-2009. PLoS ONE 2011, 6, e22927. [CrossRef]

7. De Souza, G.A.; Leversen, N.A.; Målen, H.; Wiker, H.G. Bacterial proteins with cleaved or uncleaved signal peptides of the general secretory pathway. J. Proteom. 2011, 75, 502-510. [CrossRef] [PubMed]

8. Pérez-Llarena, F.J.; Bou, G. Proteomics as a tool for studying bacterial virulence and antimicrobial resistance. Front. Microbiol. 2016, 7, 410. [CrossRef] [PubMed] 
9. Munir, A.; Kumar, N.; Ramalingam, S.B.; Tamilzhalagan, S.; Shanmugam, S.K.; Palaniappan, A.N.; Nair, D.; Priyadarshini, P.; Natarajan, M.; Tripathy, S. Identification and characterization of genetic determinants of Isoniazid and Rifampicin resistance in Mycobacterium tuberculosis in Southern India. Sci. Rep. 2019, 9, 1-13. [CrossRef] [PubMed]

10. Takiff, H.E.; Feo, O. Clinical value of whole-genome sequencing of Mycobacterium tuberculosis. Lancet Infect. Dis. 2015, 15, 1077-1090. [CrossRef]

11. Wang, Q.; Yue, J.; Zhang, L.; Xu, Y.; Chen, J.; Zhang, M.; Zhu, B.; Wang, H.; Wang, H. A newly identified 191A/C mutation in the Rv2629 gene that was significantly associated with rifampin resistance in Mycobacterium tuberculosis. J. Proteome Res. 2007, 6, 4564-4571. [CrossRef]

12. Traore, H.; Fissette, K.; Bastian, I.; Devleeschouwer, M.; Portaels, F. Detection of rifampicin resistance in Mycobacterium tuberculosis isolates from diverse countries by a commercial line probe assay as an initial indicator of multidrug resistance. Int. J. Tuberc. Lung Dis. 2000, 4, 481-484.

13. Kiet, V.S.; Lan, N.T.N.; An, D.D.; Dung, N.H.; Hoa, D.V.; van Vinh Chau, N.; Chinh, N.T.; Farrar, J.; Caws, M. Evaluation of the MTBDRsl Test for Detection of Second-Line-Drug Resistance in Mycobacterium tuberculosis. J. Clin. Microbiol. 2010, 48, $2934-2939$. [CrossRef]

14. Kim, S. Drug-susceptibility testing in tuberculosis: Methods and reliability of results. Eur. Respir. J. 2005, 25, 564-569. [CrossRef] [PubMed]

15. Walzl, G.; McNerney, R.; du Plessis, N.; Bates, M.; McHugh, T.D.; Chegou, N.N.; Zumla, A. Tuberculosis: Advances and challenges in development of new diagnostics and biomarkers. Lancet Infect. Dis. 2018, 18, e199-e210. [CrossRef]

16. Nguyen, T.N.A.; Anton-Le Berre, V.; Bañuls, A.L.; Nguyen, T.V.A. Molecular Diagnosis of Drug-Resistant Tuberculosis. A Literature Review. Front. Microbiol. 2019, 10, 794. [CrossRef] [PubMed]

17. Dubow, T.; Marjanovic, S. Population-Scale Sequencing and the Future of Genomic Medicine: Learning from Past and Present Efforts; RAND Corporation: Santa Monica, CA, USA, 2016.

18. Wu, F.; Zhong, F.; He, F. Microbial Proteomics: Approaches, Advances, and Applications. J. Bioinform. Proteom. Imaging Anal. 2016. [CrossRef]

19. Wiese, S.; Reidegeld, K.A.; Meyer, H.E.; Warscheid, B. Protein labeling by iTRAQ: A new tool for quantitative mass spectrometry in proteome research. Proteomics 2007, 7, 340-350. [CrossRef] [PubMed]

20. Chen, X.; Liu, Y.; Huang, J.; Liu, W.; Huang, J.; Zhang, Y.; Fu, W. Label-free techniques for laboratory medicine applications. Front. Lab. Med. 2017, 1, 82-85. [CrossRef]

21. Seung, K.J.; Keshavjee, S.; Rich, M.L. Multidrug-resistant tuberculosis and extensively drug-resistant tuberculosis. Cold Spring Harb. Perspect. Med. 2015, 5, a017863. [CrossRef]

22. Cole, S.; Brosch, R.; Parkhill, J.; Garnier, T.; Churcher, C.; Harris, D.; Gordon, S.; Eiglmeier, K.; Gas, S.; Barry, C., III. Deciphering the biology of Mycobacterium tuberculosis from the complete genome sequence. Nature 1998, 393, 537. [CrossRef] [PubMed]

23. Padiadpu, J.; Vashisht, R.; Chandra, N. Protein-protein interaction networks suggest different targets have different propensities for triggering drug resistance. Syst. Synth. Biol. 2010, 4, 311-322. [CrossRef] [PubMed]

24. Alland, D.; Steyn, A.J.; Weisbrod, T.; Aldrich, K.; Jacobs, W.R., Jr. Characterization of the Mycobacterium tuberculosis iniBAC promoter, a promoter that responds to cell wall biosynthesis inhibition. J. Bacteriol. 2000, 182, 1802-1811. [CrossRef]

25. Bashiri, G.; Baker, E.N. Production of recombinant proteins in Mycobacterium smegmatis for structural and functional studies. Protein Sci. 2015, 24, 1-10. [CrossRef]

26. Smith, K.L.J.; Lee, S. Inhibition of apoptosis by Rv2456c through Nuclear factor-kB extends the survival of Mycobacterium tuberculosis. Int. J. Mycobacteriol. 2016, 5, 426-436. [CrossRef] [PubMed]

27. Kaur, D.; Mathew, S.; Nair, C.G.; Begum, A.; Jainanarayan, A.K.; Sharma, M.; Brahmachari, S.K. Structure based drug discovery for designing leads for the non-toxic metabolic targets in multi drug resistant Mycobacterium tuberculosis. J. Transl. Med. 2017, 15, 261. [CrossRef] [PubMed]

28. Li, A.H.L. Identification of Virulence Determinants of Mycobacterium tuberculosis via Genetic Comparisons of a Virulent and an Attenuated Strain of Mycobacterium tuberculosis; University of British Columbia: Vancouver, BC, Canada, 2008.

29. Al-Khafaji, Z. Hypothetical proteins of Mycobacterium tuberculosis H37Rv as drug targets. Int. J. Pharma Bio. Sci. 2014, 5, 155-175.

30. Lin, X.; Kang, L.; Li, H.; Peng, X. Fluctuation of multiple metabolic pathways is required for Escherichia coli in response to chlortetracycline stress. Mol. Biosyst. 2014, 10, 901-908. [CrossRef]

31. Singh, S.; Malik, B.; Sharma, D. Metabolic pathway analysis of S. pneumoniae: An in silico approach towards drug-design. J. Bioinform. Comput. Biol. 2007, 5, 135-153. [CrossRef]

32. Wolff, K.A.; Nguyen, L. Strategies for potentiation of ethionamide and folate antagonists against Mycobacterium tuberculosis. Expert Rev. Anti-Infect. Ther. 2012, 10, 971-981. [CrossRef]

33. McLaughlin, B.; Chon, J.S.; MacGurn, J.A.; Carlsson, F.; Cheng, T.L.; Cox, J.S.; Brown, E.J. A mycobacterium ESX-1-secreted virulence factor with unique requirements for export. PLoS Pathog. 2007, 3, e105. [CrossRef]

34. Sala, C.; Odermatt, N.T.; Soler-Arnedo, P.; Gülen, M.F.; von Schultz, S.; Benjak, A.; Cole, S.T. EspL is essential for virulence and stabilizes EspE, EspF and EspH levels in Mycobacterium tuberculosis. PLoS Pathog. 2018, 14, e1007491. [CrossRef] [PubMed]

35. Rosu, V.; Bandino, E.; Cossu, A. Unraveling the transcriptional regulatory networks associated to mycobacterial cell wall defective form induction by glycine and lysozyme treatment. Microbiol. Res. 2013, 168, 153-164. [CrossRef] [PubMed] 
36. Yesilkaya, H.; Dale, J.W.; Strachan, N.J.; Forbes, K.J. Natural transposon mutagenesis of clinical isolates of Mycobacterium tuberculosis: How many genes does a pathogen need? J. Bacteriol. 2005, 187, 6726-6732. [CrossRef] [PubMed]

37. Baughn, A.D.; Deng, J.; Vilchèze, C.; Riestra, A.; Welch, J.T.; Jacobs, W.R., Jr.; Zimhony, O. Mutually Exclusive Genotypes for Pyrazinamide and 5-Chloropyrazinamide Resistance Reveal a Potential Resistance-Proofing Strategy. Antimicrob. Agents Chemother. 2011, 55, 1826. [CrossRef]

38. Jnawali, H.N.; Ryoo, S. First-and second-line drugs and drug resistance. Tuberc-Curr. Issues Diagn. Manag. 2013, 163-180. [CrossRef]

39. Brülle, J.K.; Tschumi, A.; Sander, P. Lipoproteins of slow-growing Mycobacteria carry three fatty acids and are N-acylated by Apolipoprotein N-Acyltransferase BCG_2070c. BMC Microbiol. 2013, 13, 223. [CrossRef]

40. Gu, S.; Chen, J.; Dobos, K.M.; Bradbury, E.M.; Belisle, J.T.; Chen, X. Comprehensive proteomic profiling of the membrane constituents of a Mycobacterium tuberculosis strain. Mol. Cell. Proteom. 2003, 2, 1284-1296. [CrossRef]

41. Brülle, J.K.; Grau, T.; Tschumi, A.; Auchli, Y.; Burri, R.; Polsfuss, S.; Keller, P.M.; Hunziker, P.; Sander, P. Cloning, expression and characterization of Mycobacterium tuberculosis lipoprotein LprF. Biochem. Biophys. Res. Commun. 2010, 391, 679-684. [CrossRef]

42. Biswas, R.K.; Dutta, D.; Tripathi, A.; Feng, Y.; Banerjee, M.; Singh, B.N. Identification and characterization of Rv0494: A fatty acid-responsive protein of the GntR/FadR family from Mycobacterium tuberculosis. Microbiology 2013, 159, 913-923. [CrossRef]

43. Zeng, J.; Li, Y.; Zhang, S.; He, Z.-G. A novel high-throughput B1H-ChIP method for efficiently validating and screening specific regulator-target promoter interactions. Appl. Microbiol. Biotechnol. 2012, 93, 1257-1269. [CrossRef] [PubMed]

44. Sreenu, V.B.; Kumar, P.; Nagaraju, J.; Nagarajaram, H.A. Microsatellite polymorphism across the M. tuberculosis and M. bovis genomes: Implications on genome evolution and plasticity. BMC Genom. 2006, 7, 78. [CrossRef]

45. Deng, J.; Bi, L.; Zhou, L.; Guo, S.-J.; Fleming, J.; Jiang, H.-W.; Zhou, Y.; Gu, J.; Zhong, Q.; Wang, Z.-X. Mycobacterium tuberculosis proteome microarray for global studies of protein function and immunogenicity. Cell Rep. 2014, 9, 2317-2329. [CrossRef]

46. Roupie, V.; Romano, M.; Zhang, L.; Korf, H.; Lin, M.Y.; Franken, K.L.; Ottenhoff, T.H.; Klein, M.R.; Huygen, K. Immunogenicity of eight dormancy regulon-encoded proteins of Mycobacterium tuberculosis in DNA-vaccinated and tuberculosis-infected mice. Infect. Immun. 2007, 75, 941-949. [CrossRef]

47. Goletti, D.; Butera, O.; Vanini, V.; Lauria, F.N.; Lange, C.; Franken, K.; Angeletti, C.; Ottenhoff, T.H.; Girardi, E. Response to Rv2628 latency antigen associates with cured tuberculosis and remote infection. Eur. Respir. J. 2010, 36, 135-142. [CrossRef] [PubMed]

48. Akarsu, H.; Bordes, P.; Mansour, M.; Bigot, D.-J.; Genevaux, P.; Falquet, L. TASmania: A bacterial toxin-antitoxin systems database. PLoS Comput. Biol. 2019, 15, e1006946. [CrossRef] [PubMed]

49. Williams, K.J.; Jenkins, V.A.; Barton, G.R.; Bryant, W.A.; Krishnan, N.; Robertson, B.D. Deciphering the metabolic response of M ycobacterium tuberculosis to nitrogen stress. Mol. Microbiol. 2015, 97, 1142-1157. [CrossRef] [PubMed]

50. Fontán, P.A.; Aris, V.; Alvarez, M.E.; Ghanny, S.; Cheng, J.; Soteropoulos, P.; Trevani, A.; Pine, R.; Smith, I. Mycobacterium tuberculosis sigma factor E regulon modulates the host inflammatory response. J. Infect. Dis. 2008, 198, 877-885. [CrossRef]

51. Yruela Guerrero, I.; Contreras-Moreira, B.; Magalhães, C.; Osório, N.S.; Gonzalo-Asensio, J. Mycobacterium tuberculosis Complex Exhibits Lineage-Specific Variations Affecting Protein Ductility and Epitope Recognition. Genome Biol. Evol. 2016, 12, 3751-3764.

52. Birhanu, A.G.; Yimer, S.A.; Kalayou, S.; Riaz, T.; Zegeye, E.D.; Holm-Hansen, C.; Norheim, G.; Aseffa, A.; Abebe, M.; Tønjum, T. Ample glycosylation in membrane and cell envelope proteins may explain the phenotypic diversity and virulence in the Mycobacterium tuberculosis complex. Sci. Rep. 2019, 9, 1-15. [CrossRef]

53. Hoskisson, P.A.; Hutchings, M.I. MtrAB-LpqB: A conserved three-component system in actinobacteria? Trends Microbiol. 2006, 14, 444-449. [CrossRef]

54. Banerjee, S.; Nandyala, A.; Podili, R.; Katoch, V.M.; Hasnain, S.E. Comparison of Mycobacterium tuberculosis isocitrate dehydrogenases (ICD-1 and ICD-2) reveals differences in coenzyme affinity, oligomeric state, $\mathrm{pH}$ tolerance and phylogenetic affiliation. BMC Biochem. 2005, 6, 1-14. [CrossRef]

55. Wishart, D.S.; Knox, C.; Guo, A.C.; Cheng, D.; Shrivastava, S.; Tzur, D.; Gautam, B.; Hassanali, M. DrugBank: A knowledgebase for drugs, drug actions and drug targets. Nucleic Acids Res. 2007, 36 (Suppl. 1), D901-D906. [CrossRef] [PubMed]

56. Kinnings, S.L.; Xie, L.; Fung, K.H.; Jackson, R.M.; Xie, L.; Bourne, P.E. The Mycobacterium tuberculosis Drugome and Its Polypharmacological Implications. PLoS Comput. Biol. 2010, 6, e1000976. [CrossRef] [PubMed]

57. Gorla, P.; Plocinska, R.; Sarva, K.; Satsangi, A.T.; Pandeeti, E.; Donnelly, R.; Dziadek, J.; Rajagopalan, M.; Madiraju, M.V. MtrA Response Regulator Controls Cell Division and Cell Wall Metabolism and Affects Susceptibility of Mycobacteria to the First Line Antituberculosis Drugs. Front. Microbiol. 2018, 9. [CrossRef] [PubMed]

58. Cohen, K.A.; El-Hay, T.; Wyres, K.L.; Weissbrod, O.; Munsamy, V.; Yanover, C.; Aharonov, R.; Shaham, O.; Conway, T.C.; Goldschmidt, Y.; et al. Paradoxical Hypersusceptibility of Drug-resistant Mycobacteriumtuberculosis to $\beta$-lactam Antibiotics. EBioMedicine 2016, 9, 170-179. [CrossRef]

59. Balhana, R.J.C.; Singla, A.; Sikder, M.H.; Withers, M.; Kendall, S.L. Global analyses of TetR family transcriptional regulators in mycobacteria indicates conservation across species and diversity in regulated functions. BMC Genom. 2015, 16, 479. [CrossRef]

60. Palkova, L.; Minarik, G.; Soltys, K. Draft Genome Sequencing of Acinetobacter ursingii Isolate from Healthy Human Skin, Carrying Multidrug Resistance Genes. Genome Announc. 2018, 6, e00394-18. [CrossRef]

61. Clemens, D.L.; Lee, B.-Y.; Horwitz, M.A. Purification, characterization, and genetic analysis of Mycobacterium tuberculosis urease, a potentially critical determinant of host-pathogen interaction. J. Bacteriol. 1995, 177, 5644-5652. [CrossRef] 
62. Trujillo, M.; Mauri, P.; Benazzi, L.; Comini, M.; De Palma, A.; Flohé, L.; Radi, R.; Stehr, M.; Singh, M.; Ursini, F. The mycobacterial thioredoxin peroxidase can act as a one-cysteine peroxiredoxin. J. Biol. Chem. 2006, 281, 20555-20566. [CrossRef]

63. Lata, M.; Sharma, D.; Kumar, B.; Deo, N.; Tiwari, P.K.; Bisht, D.; Venkatesan, K. Proteome analysis of ofloxacin and moxifloxacin induced Mycobacterium tuberculosis isolates by proteomic approach. Protein Pept. Lett. 2015, 22, 362-371. [CrossRef]

64. Sharma, D.; Bisht, D. Secretory Proteome Analysis of Streptomycin-Resistant Mycobacterium tuberculosis Clinical Isolates. Slas Discov. Adv. Sci. Drug Discov. 2017, 22, 1229-1238. [CrossRef]

65. Rao, A.R.; Varshney, U. Specific interaction between the ribosome recycling factor and the elongation factor G from Mycobacterium tuberculosis mediates peptidyl-tRNA release and ribosome recycling in Escherichia coli. EMBO J. 2001, 20, 2977-2986. [CrossRef]

66. Lata, M.; Sharma, D.; Deo, N.; Tiwari, P.K.; Bisht, D.; Venkatesan, K. Proteomic analysis of ofloxacin-mono resistant Mycobacterium tuberculosis isolates. J. Proteom. 2015, 127, 114-121. [CrossRef] [PubMed]

67. Guo, M.; Feng, H.; Zhang, J.; Wang, W.; Wang, Y.; Li, Y.; Gao, C.; Chen, H.; Feng, Y.; He, Z.G. Dissecting transcription regulatory pathways through a new bacterial one-hybrid reporter system. Genome Res. 2009, 19, 1301-1308. [CrossRef]

68. Simeone, R.; Bobard, A.; Lippmann, J.; Bitter, W.; Majlessi, L.; Brosch, R.; Enninga, J. Phagosomal rupture by Mycobacterium tuberculosis results in toxicity and host cell death. PLoS Pathog. 2012, 8, e1002507. [CrossRef]

69. De Jonge, M.I.; Pehau-Arnaudet, G.; Fretz, M.M.; Romain, F.; Bottai, D.; Brodin, P.; Honoré, N.; Marchal, G.; Jiskoot, W.; England, P. ESAT-6 from Mycobacterium tuberculosis dissociates from its putative chaperone CFP-10 under acidic conditions and exhibits membrane-lysing activity. J. Bacteriol. 2007, 189, 6028-6034. [CrossRef]

70. Sassetti, C.M.; Rubin, E.J. Genetic requirements for mycobacterial survival during infection. Proc. Natl. Acad. Sci. USA 2003, 100, 12989-12994. [CrossRef] [PubMed]

71. Mitra, A.; Speer, A.; Lin, K.; Ehrt, S.; Niederweis, M. PPE Surface Proteins Are Required for Heme Utilization by Mycobacterium tuberculosis. mBio 2017, 8. [CrossRef]

72. Lai, J.S.; Cheng, C.W.; Sung, T.Y.; Hsu, W.L. Computational comparative study of tuberculosis proteomes using a model learned from signal peptide structures. PLoS ONE 2012, 7, e35018. [CrossRef] [PubMed]

73. Berney, M.; Weimar, M.R.; Heikal, A.; Cook, G.M. Regulation of proline metabolism in mycobacteria and its role in carbon metabolism under hypoxia. Mol. Microbiol. 2012, 84, 664-681. [CrossRef]

74. Duan, W.; Li, X.; Ge, Y.; Yu, Z.; Li, P.; Li, J.; Qin, L.; Xie, J. Mycobacterium tuberculosis Rv1473 is a novel macrolides ABC Efflux Pump regulated by WhiB7. Future Microbiol. 2019, 14, 47-59. [CrossRef] [PubMed]

75. Bespyatykh, J.; Shitikov, E.; Butenko, I.; Altukhov, I.; Alexeev, D.; Mokrousov, I.; Dogonadze, M.; Zhuravlev, V.; Yablonsky, P.; Ilina, E.; et al. Proteome analysis of the Mycobacterium tuberculosis Beijing B0/W148 cluster. Sci. Rep. 2016, 6, 28985. [CrossRef]

76. Phong, T.Q.; Ha do, T.T.; Volker, U.; Hammer, E. Using a Label Free Quantitative Proteomics Approach to Identify Changes in Protein Abundance in Multidrug-Resistant Mycobacterium tuberculosis. Indian J. Microbiol. 2015, 55, 219-230. [CrossRef] [PubMed]

77. Wiśniewski, J.R.; Zougman, A.; Nagaraj, N.; Mann, M. Universal sample preparation method for proteome analysis. Nat. Methods 2009, 6, 359-362. [CrossRef]

78. Navarro, P.; Kuharev, J.; Gillet, L.C.; Bernhardt, O.M.; MacLean, B.; Röst, H.L.; Tate, S.A.; Tsou, C.C.; Reiter, L.; Distler, U.; et al. A multicenter study benchmarks software tools for label-free proteome quantification. Nat. Biotechnol. 2016, 34, 1130-1136. [CrossRef]

79. Cox, J.; Mann, M. MaxQuant enables high peptide identification rates, individualized p.p.b.-range mass accuracies and proteomewide protein quantification. Nat. Biotechnol. 2008, 26, 1367-1372. [CrossRef] [PubMed] 